\title{
Functional Specialization for Semantic and Phonological Processing in the Left Inferior Prefrontal Cortex ${ }^{1}$
}

\author{
Russell A. Poldrack, ${ }^{2}$ Anthony D. Wagner, Matthew W. Prull, J ohn E. Desmond, \\ Gary H. Glover, and J ohn D. E. Gabrieli \\ Stanford University, Stanford, California 94305
}

Received J une 8, 1998

Neuroimaging and neuropsychological studies have implicated left inferior prefrontal cortex (LIPC) in both semantic and phonological processing. In this study, functional magnetic resonance imaging was used to exami ne whether separate LIPC regions participate in each of these types of processing. Performance of a semantic decision task resulted in extensive LIPC activation compared to a perceptual control task. Phonological processing of words and pseudowords in a syllable-counting task resulted in activation of the dorsal aspect of the left inferior frontal gyrus near the inferior frontal sulcus (BA 44/45) compared to a perceptual control task, with greater activation for nonwords compared to words. In a di rect comparison of semantic and phonological tasks, semantic processing preferentially activated the ventral aspect of the left inferior frontal gyrus (BA 47/45). A review of the literature demonstrated a similar distinction between left prefrontal regions involved in semantic processing and phonological/lexical processing. The results suggest that a distinct region in the left inferior frontal cortex is involved in semantic processing, whereas other regions may subserve phonological processes engaged during both semantic and phonological tasks. ๑ 1999 Academic Press

The inferior cortex of the left frontal lobe is critically involved in language function. People with lesions to this region exhibit primary difficulties with speech production, though other aspects of language performance are impaired as well (see Damasio, 1992, for review). Neuroimaging studies have also provided evidence that the left frontal region is active during a widerange of language tasks, including those that do not involve overt production of speech (see Gabrieli et al., 1998, for review).

\footnotetext{
${ }^{1}$ This work was supported by NIMH and the MCDonnell-Pew Program in Cognitive Neuroscience.

2 To whom correspondence should be addressed at Department of Psychology, J ordan Hall, Stanford University, Stanford, CA 943052130. E-mail: poldrack@psych.stanford.edu.
}

The current understanding of the structure of Ianguage processing distinguishes a set of component linguistic functions: these include separable processes related to speech sounds (phonological processing); to the visual structure of written words (orthographic processes); to the meaning of linguistic tokens (semantic processing); to the structure of complex linguistic forms (syntactic processing); to the integration of phonological, semantic, and syntactic aspects of words (lexical processing); and to the programming of speech motor acts (articulatory processing).

Neuropsychological investigations suggest that each of these forms of processing may be individually impaired by brain damage, although large lesions often result in impairment of multiple processes (Caplan, 1992). The left frontal lobe has been primarily implicated in articulatory and phonological processing on the basis of neuropsychological studies. However, because brain lesions are often large and do not observe functional boundaries, it is difficult to determine whether separate linguistic functions are subserved by separate cortical regions in the left frontal lobe. In the present study, we used functional magnetic resonance imaging ( $\mathrm{fMRI}$ ) to investigate whether two classes of linguistic processing involved in the reading of written words, phonological and semantic processing, rely upon separateregions of the left inferior frontal cortex.

\section{Frontal Cortex and Semantic Processing}

I maging studies using positron emission tomography (PET) and $\mathrm{FMRI}$ have suggested that the anterior extent of the left inferior prefrontal cortex (LIPC), corresponding to Brodmann's areas 47 and 45 in the inferior frontal gyrus, is activeduring word-level semantic processing, such as making semantic decisions about words (Demb et al., 1995; Gabrieli et al., 1996; Kapur et al., 1994b; Wagner et al., 1998) or generating words based on semantic relationships (Klein et al., 1995; Petersen et al., 1988). Demb et al. (1995) examined whether LIPC activation in a semantic decision task was a function of task difficulty and found that 
LIPC was activated during a semantic decision task even when the perceptual baseline task was more difficult (as measured by response time). This result rules out the possibility that brain activation in the semantic task was a function of task difficulty rather than semantic processing per se.

Evidence for the specificity of LIPC activation to semantic processing comes from a study that examined repetition priming effects in a semantic decision task (Demb et al., 1995). Repetition of items in a semantic decision task (abstract/concrete judgment) resulted in reduced LIPC activation for the repeated compared to the original presentation. Performing a perceptual decision task (uppercase/lowercase) repeatedly resulted in no such changes in prefrontal activation, suggesting that the changes were specific to semantic processing. Wagner et al. (1997a) further examined the process specificity of such item repetition effects and found that items initially encountered in a perceptual decision task did not result in later decreases in activation on a semantic decision task, whereas items initially encountered in a semantic decision task resulted in decreases in LIPC activation when reprocessed semantically. A study by Wagner et al. (1997b) demonstrated the generality of LIPC involvement in semantic processing. Subjects were presented with pictures or words and made category decisions (living/ nonliving) for each item. Activation of LIPC decreased with repetition both for words and for pictures, suggesting that LIPC plays a general role in semantic processing (see also Vandenberghe et al ., 1996).

The role of the frontal cortex in semantic processing has also been examined using other methods. A study using scalp recordings with high-density electrodes found differences in electrical activity over the frontal cortex between word reading and semantic generation tasks, with the source of the difference localized to the ventral left frontal cortex (Abdullaev and Posner, 1998). Another study using chronically implanted depth electrodes in LIPC (BA 47) found greater activity in that region related to semantic decision relative to a perceptual decision (Abdullaev and Bechtereva, 1993). In a study combining intraoperative stimulation with PET (Klein et al., 1997), stimulation of an LIPC region disrupted synonym generation but not word repetition, and the same region exhibited PET activation for synonym generation compared to word repetition. Neuropsychological studies provideadditional evidencethat LIPC is involved in semantic processing of words. Swick and Knight (1996) examined abstract/concrete and living/nonliving judgments in patients with lesions to the LIPC, the left superior prefrontal cortex, or the right prefrontal cortex. Patients with lesions to the LIPC were impaired on the living/nonliving task relative to patients with lesions to the left superior prefrontal cortex or the right prefrontal area. These data converge with imaging studies to strongly suggest that activation in the LIPC is directly related to semantic processing of words.

\section{Frontal Cortex and Phonological Processing}

The LIPC has also been implicated in phonological processing on the basis of imaging and neuropsychological studies. Studies using PET have found activation of the LIPC during tasks that require judgments about individual phonemes, such as phonetic monitoring (Demonet et al., 1992; Zatorre et al., 1996), and other tasks that require processing of phonological information such as rhyming judgments (Sergent et al., 1992) and the generation of rhymes (Klein et al., 1995). Similar activations have been found during tasks involving visually presented nonwords (Pugh et al., 1996). Tasks involving the reading of nonwords are thought to require phonological recoding in order to translate novel orthographic information into phonological information, whereas tasks involving familiar words can be performed by direct retrieving phonological representations from the lexicon (Coltheart, 1985).

Lesions to the LIPC may also impair phonological processing. F iez and Petersen (1998) have reviewed the evidence for phonological dyslexia (an impairment in the ability to derive phonological information from orthographic information) in patients with damage to the left inferior frontal region. Across studies, six of seven patients with confirmed damage to the left frontal region (sometimes accompanied by other lesions) exhibited deficits in reading nonwords, erroneously producing real words in response to visually presented nonwords. This review provides preliminary evidence in favor for a role of the left frontal cortex in phonological processing, though further work is necessary to fully characterize the anatomical and linguistic nature of the deficit.

\section{Phonol ogical vs Semantic Processing in F rontal Cortex}

One important question regards whether semantic and phonological processing relies upon separate functional regions in the LIPC. Resolving this question is not only important from a brain-mapping perspective, but can also shed light upon the basic structure of language processing. Common activations for phonol ogical and semantic processing in the LIPC would suggest common underlying cognitive processes, whereas separate activations suggest distinct processes.

There are reasons to believe that semantic and phonological processing might be closely related. The first is the well-known automaticity of semantic processing (Neely, 1977). It may be the case that words that are processed to the level of phonology are automatically processed semantically as well, whereas words processed in a superficial visual manner (as in a case 
judgment task) might not engender the same level of automatic semantic processing. Conversely, phonological information may exert an automatic influence on semantic processing. Van Orden et al . (1988) found that subjects made phonologically driven false alarms in a category decision task, such as accepting "rows" as a flower, suggesting that phonological information automatically influenced performance on the semantic task. Such findings have led some (e.g., Van Orden et al., 1988) to argue that reading words for meaning is mediated by phonological processing; however, neuropsychological evidenceshows that patients with impairments in phonological processing may perform well on semantic tasks (Hanley and McDonnell, 1997; Shelton and Weinrich, 1997), suggesting that phonological mediation may not be necessary. Functional neuroimaging can help address this issue by determining the degree to which semantic and phonological processing results in distinct patterns of neural activation.

\section{The Current Study}

The study presented here directly examined the role of LIPC in semantic and phonological processing using fMRI. Several previous imaging studies directly comparing semantic and phonological processing have not found differences in inferior frontal activation between semantic and phonological tasks (Klein et al., 1995; Price et al., 1997; Pugh et al., 1996). Other studies have found regions of greater activation for semantic processing relative to phonological processing (Shaywitz et al., 1995). We attempted to clarify these previous studies by presenting four scans with task comparisons designed to isolate specific classes of linguistic processing. One scan compared a semantic decision (abstract/ concrete decision) with a perceptual decision task (uppercase/lowercase decision) in order to isolate semantic, phonological, and lexical processing. Another scan compared a phonological task (syllable counting) with the same perceptual decision task in order to isolate phonological processing of words, which may involve direct retrieval of phonological word-form information. A third scan compared a phonological task (syllable counting) using nonwords with the perceptual baseline task; because reading nonwords likely requires translation of orthographic to phonological features, this task was thought to isolate phonological recoding operations. A fourth scan directly compared the semantic decision task with the phonological task (with words), in order to directly isolate the regions involved specifically in semantic or phonological processing. These are referred to as the semantic, phonological, pseudoword phonological, and direct comparison scans, respectively. Together these scans allow the determination of the whether separate regions in the LIPC subserve these linguistic processes.

The syllable-counting task used in the present study differs from the tasks used in a number of previous studies of phonological processing, such as phoneme monitoring or rhyme judgments. Whereas phoneme monitoring tasks require access to individual phonemes, the syllable-counting task requires access to individual syllables, which are composed of clusters of phonemes. Thesyllabic level of representation is important during both language comprehension and language production. For example, the syllable is thought to be the basic unit of organization for phonological encoding, which is the stage in speech production at which a phonetic plan is assembled (Levelt, 1993). This suggests that the syllable-counting task might engage frontal regions involved in speech production, and one previous study (Price et al., 1997) found activation of the left prefrontal cortex during syllable counting (at a lenient threshold). Rhyme judgments may be more similar to syllable counting than phoneme discrimination, since rhyme judgments also involve processing of features greater than a single phoneme. The syllablecounting task introduces an additional requirement to maintain a count, which is not required for other phonological tasks. However, the small number of syllables involved (one to three) suggests that subjects may subitize the units (i.e., enumerate them without counting). When performed with pseudowords, the syllable-counting task also requires additional phonological processing in the form of phonological recoding, which may result in activation of additional regions.

\section{METHODS}

\section{Subjects}

Subjects were eight volunteers (five male and three female, seven right-handed and one left-handed) from the Stanford community who participated for $\$ 30$. All subjects were native speakers of English. Informed consent was obtained from each subject prior to the experiment.

\section{Materials}

Three 144-word lists were constructed from a previously used set of abstract and concrete words (see Gabrieli et al., 1996); these word lists are presented in Appendix A. Word frequency and word length did not differ significantly between lists (P's > 0.2). Across lists, mean word frequency (Kucera and Francis, 1982) was 63.4 for abstract words and 47.0 for concrete words. Each list was broken into 12 blocks of 12 words; each block consisted of half abstract and half concrete words, half uppercase and half lowercase words, and half two-syllable and half one- and three-syllable words. Thus, each list could be used interchangeably in each of three tasks: abstract/concrete judgment, case judgment, and syllable counting. Pseudowords used in the 
experiment were chosen from a set of pronounceable nonwords created by changing one consonant in a set of medium-frequency English words; these nonwords are also presented in Appendix A. Each item appeared only once during the entire experiment for each subject.

\section{Procedure}

Subjects participated in one scanning session lasting approximately $90 \mathrm{~min}$. Four functional scans were administered during the session; the order of these scans in the session and the assignment of word lists to particular scans was counterbalanced across subjects. Across the four scans, the subjects performed three tasks in different combinations. In the case judgment task, the subject pressed a response button depending upon the case of the letters in which the word was presented. In the category judgment task, the subject pressed the response button depending upon whether the word was abstract or concrete. In the syllable judgment task, the subject pressed the response button depending upon the number of syllables in the word or pseudoword. Half of the subjects pressed the response button for abstract words, uppercase words, and twosyllable words. The other half of the subjects pressed the response button for concrete words, lowercase words, and words that did not have two syllables.

In each scan, the two tasks being compared were alternated each $34.17 \mathrm{~s}$ for six cycles of alternation. In the Semantic scan, the semantic judgment and case judgment tasks were alternated. In the Phonological scan, the syllable judgment (on real words) and case judgment tasks were alternated. The P seudoword P honological scan was identical in procedure to the Phonological scan, except that the stimuli were pronounceable nonwords. In the Direct Comparison scan, the semantic judgment task and syllable judgment task (with real words) were alternated in order to directly compare semantic and phonological processing. Each individual item was presented for $1.5 \mathrm{~s}$ with a 1.13-s interstimulus interval. An instruction card was presented at the beginning of each block of trials, with the same timing as the stimuli.

Stimuli were generated by a Macintosh computer and back projected onto a screen located above the subject's neck via a magnet-compatible projector; the projected image appeared on a mirror mounted above the subject's head. Subjects responded by pressing an optical switch with the right hand. The responses were collected by a computer interfaced with the optical switch using the PsyScope button box (Cohen et al., 1993).

\section{fMRI Procedures}

I maging was performed with a 1.5-T whole-body MRI scanner (GE Medical Systems Signa). A prototype receive-only whole-head coil was used for signal reception. Head movement was minimized using a "bite-bar" formed with each participant's dental impression. A T2*-sensitive gradient-echo spiral sequence (Glover and Lai, 1998) was used for functional imaging with parameters of TE $=40 \mathrm{~ms}, \mathrm{TR}=900 \mathrm{~ms}$, flip angle $=$ $70^{\circ}, \mathrm{FOV}=36 \mathrm{~cm}$, and inplane resolution $=2.35 \mathrm{~mm}$. Four spiral interleaves were obtained for each image, for a total acquisition time of $360 \mathrm{~ms}$ per image slice (3600 ms per image volume). The onset of the scanning session was controlled by the experimental presentation program via a TTL output, allowing precise synchronization of the stimulus presentation and scanner onset.

In each experiment, ten 6-mm-thick slices were acquired separately in the coronal plane of the Talairach and Tournoux (1988) atlas from the anterior commissure to the frontal pole, with a 1-mm interslice interval. Figure 1 presents an example of such a set of slices overlaid on a saggital localizing image. Functional images were acquired continuously every $3.6 \mathrm{~s}$ over the course of each 410-s experiment, for a total of 114 images. T1-weighted flow-compensated spin-echo anatomy images were acquired for each of the slices imaged in the functional scans.

A feature of the spiral acquisition technique is that off-resonance resulting from magnetic fiel d heterogeneity or T2* variations causes only image blurring rather than spatial distortions as in echo-planar imaging or conventional gradient-recalled methods (Noll et al., 1992). This blurring was corrected during reconstruction from a field map made using phase images obtained at two different echo times for each spatial slice (I rarrazabal et al., 1996) Registration of the functional images and the spin-echo anatomic images required no correction for distortion.

\section{Data Analysis}

Functional image processing was performed offline after transferring the raw data to a Sun SparcStation. Raw functional images were motion corrected in the inplane dimensions using AIR 3.0 (Woods et al., 1992) and then spatially filtered in three dimensions using a Gaussian filter (5 $\mathrm{mm}$ full width at half-maximum). The data were then analyzed using the cross-correlation method described by Friston et al. (1994). The activity of each pixel was correlated to a reference function obtained by convolving the square wave describing the task alternation with an estimate of the participant's hemodynamic response function. For each scan in the present experiment, the frequency of the square wave describing the task alternation was $0.014634 \mathrm{~Hz}$ (6 cycles/410 s). These correlation values were then normalized to create a functional image (SPM $\{Z\}$ ) for each individual scan for each subject.

Averaged functional images across the eight subjects 


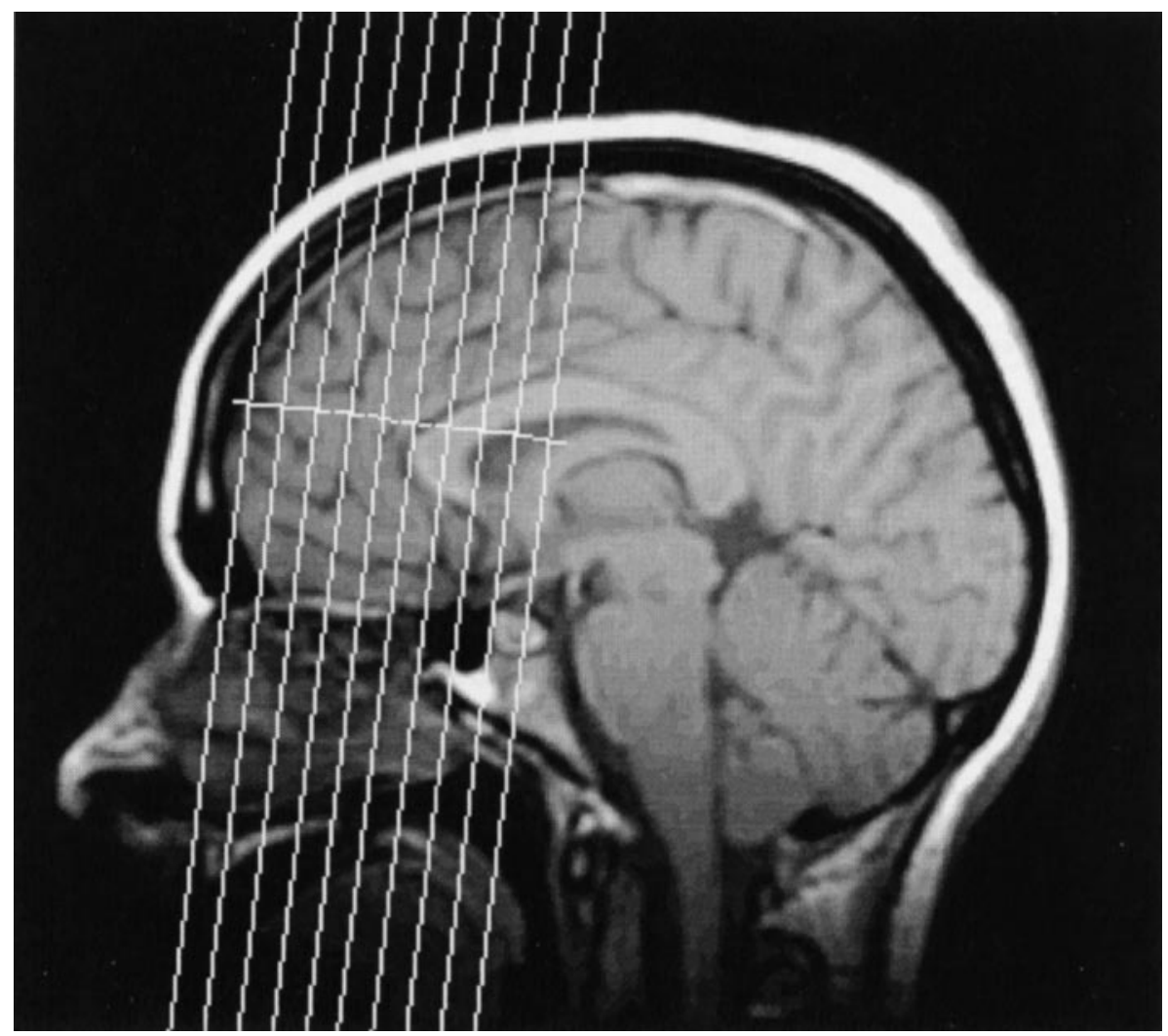

FIG. 1. Example of fMRI slice selection.

were formed for each scan by warping the functional images for each participant onto a reference template from the Talairach and Tournoux (1988) atlas using the nonlinear WARP TRI procedure in IDL (Research Systems, Inc., Boulder, CO). Functional activation maps were constructed by selecting pixels whose averaged correlation values exceeded a criterion of $Z \geq 1.96$ ( $P=0.05$, two-tailed), along with a median filter of three pixels. Cluster maxima were included in the activation tables bel ow if they had a $Z$ value of at least 1.96 and a cluster size of at least six inplane voxels and were at least two slices away from the nearest maximum in the same cluster.

Data were also analyzed using a paired comparison approach, which was performed using double subtraction between pairs of scans; this approach allows comparison of activations across separatetask comparisons (cf. Poldrack et al., 1998). In this case, the approach allowed examination of convergence of comparisons across scans with the results from individual scans. After warping to the reference template, Z maps from each of the two scans being compared were subtracted and then averaged across subjects. The resultant map is distributed under the null hypothesis as a standard normal variate with mean of zero and standard deviation of sqrt( $\mathrm{N})$ where $\mathrm{N}$ is the number of subjects. Two comparisons were examined using this analysis for comparison with the Direct Comparison scan (Semantic - Syllable judgment): Semantic versus Phonological scans [(Semantic - Case) - (Syllable Case)] and Semantic versus Pseudoword Phonological [(Semantic - Case) - (Pseudoword Syllable - Case)].

\section{RESULTS}

\section{Behavioral Results}

Response times and accuracy for each of the four scans are presented in Table 1. Case judgments were faster than semantic decisions in the Semantic scan, $\mathrm{t}(7)=7.15, \mathrm{P}<0.001$, and were faster than phonological decisions in the Phonological scan, $\mathrm{t}(7)=5.49, \mathrm{P}<$ 0.001 . In the Direct Comparison scan, there was no significant difference between responsetimes for phonological and semantic decisions, $\mathrm{t}(7)=0.059, \mathrm{P}>0.95$; five subjects were slower on semantic decisions and three were slower on phonological decisions. In the Pseudoword Phonological scan, phonological decisions were slower than case judgments, $\mathrm{t}(7)=7.12, \mathrm{P}<$ 0.001 .

\section{FMRI Results: LIPC}

Table 2 presents the Talairach locations for significant clusters of activation and deactivation in each of 
TABLE 1

Response Time and Accuracy for Each Scan (Standard Error in Parentheses)

\begin{tabular}{lcc}
\hline \multicolumn{1}{c}{ Scan and task } & RT & Accuracy \\
\hline $\begin{array}{l}\text { Semantic vs Case } \\
\quad \text { Case }\end{array}$ & $527(31)$ & $0.99(0.005)$ \\
$\quad$ Category & $843(51)$ & $0.89(0.038)$ \\
$\begin{array}{l}\text { Phonological vs Case } \\
\quad \text { Case }\end{array}$ & $537(24)$ & $0.99(0.007)$ \\
$\quad$ Syllable & $805(43)$ & $0.96(0.023)$ \\
Semantic vs Phonol ogical & & \\
$\quad$ Syllable & $830(70)$ & $0.91(0.036)$ \\
$\quad$ Category & $835(41)$ & $0.81(0.048)$ \\
Pseudoword Phonological vs Case & & \\
$\quad$ Case & $497(29)$ & $0.91(0.082)$ \\
$\quad$ Nonword Syllable & $907(54)$ & $0.75(0.089)$ \\
\hline
\end{tabular}

the four scans for the entire scan volume averaged over all subjects; regions outside the inferior frontal cortex are included for completeness but will not be discussed here. Figure 2 presents the averaged functional activation maps over all subjects for the region encompassing the left inferior frontal cortex, whereas Fig. 3 presents data from an individual subject for each scan. There was significant LIPC activation in the Semantic scan, which compared the abstract/concrete decision to the uppercase/lowercase decision. This activation extended through Brodmann's areas 44, 45, and 47. Significant activation was also present in theright inferior prefrontal cortex (RIPC); this bilateral pattern of activation in the Semantic scan was observed in six of the eight participants. Other studies of semantic processing have also found RIPC activation during semantic processing (e.g., Wagner et al., 1998). The LIPC activation in the Semantic scan extended anteriorly to the frontal pole, as did RIPC activation.

In the Phonological scan, there was a limited region of activation in the dorsal portion of the left inferior frontal gyrus, near the inferior frontal sulcus (BA 45). Activation was also found in the right inferior frontal gyrus (BA 44).

In the Direct Comparison scan, there were significant regions of activation in the anterior LIPC (BA 47/45) and posterior LIPC (BA 44) for semantic processing compared directly to phonol ogical processing. There was no evidence for greater phonol ogical-related activation than semantic-related activation in the left inferior frontal gyrus. However, the right inferior frontal cortex exhibited greater activation for the phonological task compared to the semantic task.

In the Pseudoword Phonological condition, there was significant activation of the inferior frontal gyrus during phonological decisions when compared to case judgments; this activation fell near the inferior frontal sulcus in the dorsal aspect of the gyrus. Activation was also observed in the superior and posterior section of the inferior frontal gyrus (BA 44/45). Significant right inferior frontal activation was also observed during this task.

\section{Between-Scan Comparisons}

Task comparisons across separate scans were performed using double subtraction as described above; activations and deactivations for these comparisons are listed in Table 2. Activation in the Semantic scan was first compared to activation in the Phonological scan. There was an area of significantly greater activation for semantic processing extending along the left inferior frontal gyrus for several centimeters, through BA 44, 45,47 , and 10. There were also two regions of significantly greater semantic activation in the right inferior frontal gyrus, posteriorly in BA 44 and anteriorly in BA 47. The double subtraction results thus confirmed the results from the individual scan comparisons between semantic and phonological processing.

Activation in the Semantic scan was also compared to that in the Pseudoword Phonological scan to determine whether the heightened phonological demands of the pseudoword task would offset the activation in left inferior prefrontal regions in the semantic task. There was significantly greater activation in the left inferior prefrontal region for semantic processing, extending through BA 45 and 47 . There was also a region of greater activation for semantic processing in the right inferior frontal cortex.

\section{DISCUSSION}

Our examination of semantic and phonological processing in the left inferior prefrontal cortex demonstrated the existence of a region in the left inferior frontal gyrus whose activity was specifically related to semantic processing. The anterior/ventral extent of the gyrus was more active during semantic than phonol ogical processing, whereas a more posterior/dorsal region (near the inferior frontal sulcus) was active in relation to both semantic and phonological processing. There was no evidence of greater activation in the left inferior frontal gyrus for phonological relative to semantic processing. Comparisons between scans provided converging evidence with the results from individual scans, demonstrating that semantic processing resulted in greater activity in the anterior/inferior LIFG than phonological processing for either words or pseudowords. These results suggest that phonological processing is automatically engaged during the performance of a semantic task, but that some regions in the LIPC are specifically related to semantic processing. The dissociation between anterior/ventral and posterior/dorsal regions is al so consistent with the framework proposed by Fiez (1997) for semantic and phonological processing in the frontal cortex. 
Talairach

coordinates Maximum

Comparison

$\begin{array}{llll}x & y & z & Z\end{array}$

Semantic $>$ Case

L inf frontal gyr (BA 47)

Ant cingulate (BA 32)

$L$ inf frontal gyr (BA 44)

R mid frontal gyr (BA 10)

Sup frontal gyr (BA 8)

Ant cingulate (BA 24/32)

$R$ inf frontal gyr (BA 45/47)

$\mathrm{R}$ orbitofrontal cortex (BA 11)

$R$ inf frontal gyr (BA 44)

$L$ inf frontal gyr (BA 10)

$L$ inf frontal gyr (BA 47)

$R$ inf frontal gyr (BA 45)

$\mathrm{R}$ caudate

$L$ caudate

L sup frontal gyr (BA 10)

L orbitofrontal cortex (BA 11)

L sup frontal gyr (BA 9)

$L$ caudate

L mid frontal gyr (BA 6)

Case $>$ Semantic

$L$ mid frontal gyr (BA 8/9)

Med frontal gyr (BA 10)

Ant cingulate (BA 32/24)

Phonological $>$ Case

$\begin{array}{llll}-46 & 20 & -3 & 7.3\end{array}$

$\begin{array}{llll}-1 & 20 & 42 & 6.96\end{array}$

$\begin{array}{llll}-49 & 8 & 26 & 6.14\end{array}$

$\begin{array}{llll}38 & 50 & 15 & 5.91\end{array}$

$\begin{array}{llll}-1 & 35 & 47 & 5.15\end{array}$

$\begin{array}{llll}-2 & 8 & 45 & 5.09\end{array}$

$\begin{array}{llll}34 & 20 & 0 & 5.06\end{array}$

$\begin{array}{llll}7 & 60 & -18 & 4.72\end{array}$

$\begin{array}{llll}52 & 8 & 26 & 4.53\end{array}$

$\begin{array}{rrrr}-46 & 50 & 1 & 4.41\end{array}$

$\begin{array}{llll}-35 & 35 & -1 & 4.38\end{array}$

$\begin{array}{llll}43 & 35 & 13 & 4.24\end{array}$

$\begin{array}{llll}12 & 8 & 12 & 4.13\end{array}$

$\begin{array}{llll}-12 & 0 & 18 & 3.87\end{array}$

$\begin{array}{llll}-23 & 60 & -7 & 3.82\end{array}$

$\begin{array}{llll}-25 & 50 & -16 & 3.53\end{array}$

$\begin{array}{llll}-5 & 50 & 33 & 3.22\end{array}$

$\begin{array}{llll}-10 & 16 & 11 & 3.05\end{array}$

$\begin{array}{llll}-39 & 0 & 47 & 2.8\end{array}$

$\begin{array}{llll}-36 & 35 & 37 & 3.73\end{array}$

$\begin{array}{llll}0 & 55 & 0 & 3.54\end{array}$

$\begin{array}{llll}-2 & 40 & 0 & 3.28\end{array}$

White matter

Ant cingulate (BA 24/32)

$\mathrm{R}$ mid frontal gyr (BA 8/9)

$L$ inf frontal gyr (BA 45)

Ant cingulate (BA 24/32)

$R$ inf frontal gyr (BA 44)

$\mathrm{L}$ premotor (BA 6)

Case $>$ Phonological

L sup/mid frontal gyr (BA 8/9)

Med frontal gyr (BA 9)

L sup frontal gyr (BA 8)

$\mathrm{R}$ mid frontal gyr (BA 10)

R sup frontal gyr (BA 10)

Med frontal gyr (BA 9/10)

Semantic $>$ Phonological

Sup frontal gyr (BA 9)

Medial frontal gyrus (BA 8)

$L$ inf frontal gyr (BA 44)

$L$ sup frontal gyr (BA 6)

$L$ inf frontal gyr (BA 47)

$L$ inf frontal gyr (BA 47)

Phonological > Semantic

L mid frontal gyr (BA 9/46)

R premotor (BA 6)

Corpus callosum

R inf/mid frontal gyr (BA 45/9)

L premotor (BA 6)

$R$ inf frontal gyr (BA 45)

$R$ inf frontal gyr (BA 44)

Gyrus rectus

Med frontal gyr (BA 10)

$R$ inf frontal gyr (BA 10)

R sup frontal gyr (BA 10)

Ant cingulate/med frontal gyr (BA 32/6)

$\begin{array}{lll}32 & 35 & 22\end{array}$

$\begin{array}{lll}-3 & 8 & 36\end{array}$

$\begin{array}{lll}38 & 20 & 33\end{array}$

$\begin{array}{lll}-47 & 28 & 16\end{array}$

$\begin{array}{lll}5 & 20 & 30\end{array}$

$\begin{array}{lll}60 & 8 & 27\end{array}$

$\begin{array}{lll}-46 & 0 & 24\end{array}$

$\begin{array}{lll}-23 & 40 & 34\end{array}$

$\begin{array}{lll}-1 & 40 & 20\end{array}$

$\begin{array}{lll}-17 & 28 & 43\end{array}$

$\begin{array}{lll}30 & 55 & 20\end{array}$

$\begin{array}{lll}22 & 60 & -10\end{array}$

$\begin{array}{ll}-1 & 55\end{array}$

$\begin{array}{llll}-7 & 50 & 31 & 4.69\end{array}$

$\begin{array}{llll}-4 & 35 & 48 & 4.61\end{array}$

$\begin{array}{llll}-53 & 16 & 25 & 3.68\end{array}$

$\begin{array}{llll}4 & 20 & 56 & 3.39\end{array}$

$\begin{array}{llll}-37 & 28 & -9 & 3.31\end{array}$

$\begin{array}{llll}-42 & 40 & -8 & 2.74\end{array}$

$\begin{array}{llll}-42 & 35 & 26 & 4.02\end{array}$

$\begin{array}{llll}49 & 0 & 16 & 3.68\end{array}$

$\begin{array}{llll}15 & 35 & 3 & 3.37\end{array}$

$\begin{array}{llll}33 & 20 & 41 & 3.17\end{array}$

$\begin{array}{llll}-47 & 0 & 13 & 3.11\end{array}$

$\begin{array}{llll}48 & 35 & 7 & 3.03\end{array}$

$\begin{array}{llll}47 & 8 & 37 & 3\end{array}$

$\begin{array}{llll}0 & 50 & -26 & 2.97\end{array}$

$\begin{array}{rrrr}10 & 50 & 4 & 2.94\end{array}$

$\begin{array}{llll}41 & 50 & 2 & 2.72\end{array}$

$\begin{array}{llll}27 & 60 & 5 & 2.5\end{array}$

$\begin{array}{llll}-1 & 0 & 47 & 2.46\end{array}$

Pseudoword Phonological $>$ Case

$L$ inf frontal gyrus (BA 44)

$\mathrm{R}$ inf frontal gyr (BA 45)

Ant cingulate/med frontal gyr (BA 24/32)

Ant cingulate (BA 32)

R premotor (BA 6)

$L$ inf frontal gyrus (BA 45)

$\mathrm{R}$ inf/mid frontal gyr (BA 46/10)

$\begin{array}{rrrr}-56 & 8 & 23 & 6.65 \\ 39 & 28 & 16 & 6.19 \\ 0 & 8 & 43 & 6.05 \\ 0 & 20 & 42 & 5.91 \\ 42 & 0 & 25 & 5.91 \\ -48 & 20 & 26 & 5.12 \\ 43 & 40 & 12 & 5.09\end{array}$

Talairach

\begin{tabular}{|c|c|c|c|c|}
\hline \multirow[b]{2}{*}{ Comparison } & \multicolumn{3}{|c|}{$\begin{array}{l}\text { Talairach } \\
\text { coordinates }\end{array}$} & \multirow{2}{*}{$\begin{array}{c}\text { Maximum } \\
\mathrm{Z}\end{array}$} \\
\hline & $\mathrm{x}$ & $\mathrm{y}$ & $\mathrm{z}$ & \\
\hline R inf frontal gyr (BA 44/9) & 48 & 16 & 24 & 4.98 \\
\hline$L$ inf frontal gyrus (BA 45) & -50 & 35 & 12 & 4.55 \\
\hline R caudate & 12 & 0 & 14 & 3.93 \\
\hline L putamen & -17 & 8 & 7 & 3.65 \\
\hline Sup frontal gyr (BA 8) & 0 & 35 & 46 & 3.08 \\
\hline R mid frontal gyr (BA 10) & 41 & 55 & 5 & 3.08 \\
\hline White matter & -17 & 28 & 2 & 2.83 \\
\hline \multicolumn{5}{|l|}{ Case $>$ Pseudoword Phonological } \\
\hline Med frontal gyr (BA 10) & -2 & 55 & -10 & 4.95 \\
\hline R mid/sup frontal gyr (BA 8/9) & 18 & 40 & 43 & 3.85 \\
\hline L mid frontal gyr (BA 8/9) & -27 & 20 & 43 & 3.71 \\
\hline Ant cingulate (BA 32) & -3 & 40 & -3 & 3.68 \\
\hline Med frontal gyr (BA 9) & 1 & 50 & 21 & 3.65 \\
\hline Ant cingulate (BA 24/32) & -7 & 28 & -6 & 3.39 \\
\hline Ant insula & 33 & 8 & -8 & 3.14 \\
\hline L mid/sup frontal gyr (BA 8/9) & -22 & 35 & 49 & 3.03 \\
\hline \multicolumn{5}{|c|}{ Semantic $>$ Phonological (double subtraction) } \\
\hline L inf frontal gyr (BA 45/47) & -44 & 20 & -1 & 6.25 \\
\hline $\mathrm{R}$ inf/mid frontal gyr (BA 9/44) & 49 & 16 & 30 & 5.74 \\
\hline $\mathrm{R}$ inf frontal gyr (BA 47) & 47 & 28 & -9 & 5.2 \\
\hline $\mathrm{R}$ inf frontal gyr (BA 47) & 39 & 40 & -10 & 5.15 \\
\hline R sup frontal gyr (BA 11) & 15 & 55 & -14 & 4.92 \\
\hline$L$ inf frontal gyr (BA 44) & -47 & 8 & 21 & 4.86 \\
\hline $\mathrm{R}$ caudate & 10 & 8 & 11 & 4.84 \\
\hline L sub frontal gyr (BA 11) & -24 & 50 & -16 & 4.58 \\
\hline R mid frontal gyr (BA 10) & 34 & 55 & 7 & 4.53 \\
\hline Med frontal gyr (BA 9/10) & -5 & 55 & 20 & 4.5 \\
\hline L inf frontal gyr (BA 45/47) & -35 & 35 & -2 & 4.5 \\
\hline L sub frontal gyr (BA 11) & -22 & 60 & -8 & 3.96 \\
\hline White matter & -12 & 0 & 23 & 3.62 \\
\hline $\mathrm{L}$ caudate & -12 & 16 & 12 & 3.59 \\
\hline Ant cingulate (BA 32) & -9 & 40 & 10 & 3.42 \\
\hline Corpus callosum & -8 & 28 & 12 & 2.52 \\
\hline \multicolumn{5}{|c|}{ Phonological > Semantic (double subtraction) } \\
\hline L mid frontal gyr (BA 8/9) & -36 & 35 & 38 & 4.04 \\
\hline R mid frontal gyr (BA 8/9) & 32 & 28 & 32 & 3.93 \\
\hline R premotor (BA 6) & 55 & 0 & 11 & 3.17 \\
\hline
\end{tabular}

Semantic > Pseudoword Phonological (double subtraction)

L sup frontal gyr (BA 6/8)

Med frontal gyr/ant cingulate (BA 32/8)

$L$ inf frontal gyr (BA 45)

L sup frontal gyr (BA 6)

L sup frontal gyr (BA 9)

R sup frontal gyr (BA 8)

$L$ inf frontal gyr (BA 10)

$L$ inf frontal gyr (BA 47)

$L$ mid frontal gyr (BA 6)

$R$ inf frontal gyr (BA 47)

$L$ inf frontal gyr (BA 44)

$R$ inf frontal gyr (BA 47)

$L$ caudate

$\mathrm{R}$ inf/mid frontal gyr (BA 6/44)

$\mathrm{R}$ caudate/putamen

$R$ sup frontal gyr (BA 10)

$\mathrm{R}$ mid frontal gyr (BA 10)

Ant insula

Pseudoword Phonological $>$ Semantic (double subtraction)

R premotor (BA 6)

$\mathrm{R}$ mid frontal gyr (BA 8/9)

$\mathrm{R}$ mid frontal gyr (BA 8/9)

R mid frontal gyr (BA 9/46)

$\mathrm{R}$ mid frontal gyr (BA 6)

$\mathrm{R}$ ant cingulate (BA 24)

$R$ ant insula (BA 13)

Med/sup frontal gyr (BA 6)

$L$ ant insula (BA 13)

White matter $\begin{array}{rrr}-10 & 28 & 54\end{array}$

$\begin{array}{lll}-7 & 35 & 34\end{array}$

$\begin{array}{lll}-55 & 20 & 17\end{array}$

$\begin{array}{lll}-6 & 16 & 54\end{array}$

$\begin{array}{lll}-13 & 55 & 24\end{array}$

$\begin{array}{lll}17 & 40 & 42\end{array}$

$\begin{array}{lll}-43 & 50 & 0\end{array}$

$\begin{array}{lll}-33 & 35 & -9\end{array}$

$\begin{array}{lll}-39 & 0 & 55\end{array}$

$\begin{array}{lll}49 & 20 & -7\end{array}$

$\begin{array}{lrr}-44 & 8 & 26\end{array}$

$\begin{array}{lll}41 & 35 & -8\end{array}$

$\begin{array}{lll}-12 & 16 & 13\end{array}$

$\begin{array}{lll}52 & 8 & 39\end{array}$

$\begin{array}{lll}3 & 16 & 4\end{array}$

$\begin{array}{lll}15 & 60 & 24\end{array}$

$\begin{array}{lll}32 & 55 \quad 5\end{array}$

$\begin{array}{lll}-34 & 8 & -6\end{array}$

6.05

5.49

5.09

4.78

4.7

4.5

4.41

4.21

3.87

3.73

3.34

3.17

3

2.97

2.91

2.72

2.66

2.4

$\begin{array}{rrrl}40 & 0 & 25 & 5.63 \\ 33 & 28 & 38 & 5.15 \\ -37 & 35 & 36 & 4.5 \\ 39 & 40 & 22 & 4.16 \\ 29 & 0 & 61 & 4.02 \\ 8 & 8 & 31 & 3.93 \\ 37 & 16 & 9 & 3.65 \\ 3 & 0 & 70 & 3.22 \\ -32 & 16 & 10 & 2.89 \\ 30 & 0 & 5 & 2.6\end{array}$




\section{Semantic vs. Case Judgment}

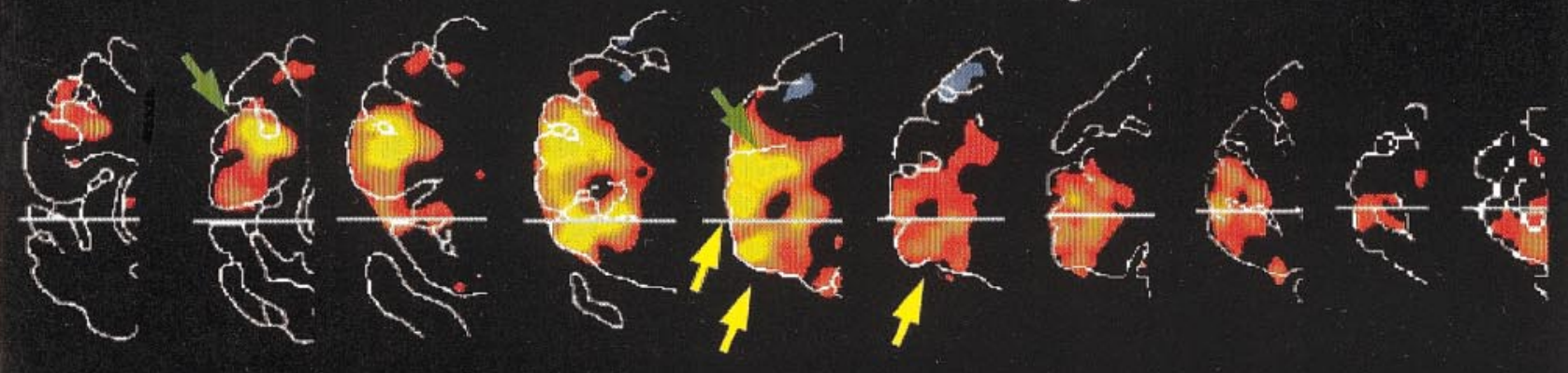

\section{Phonological vs. Case Judgment}
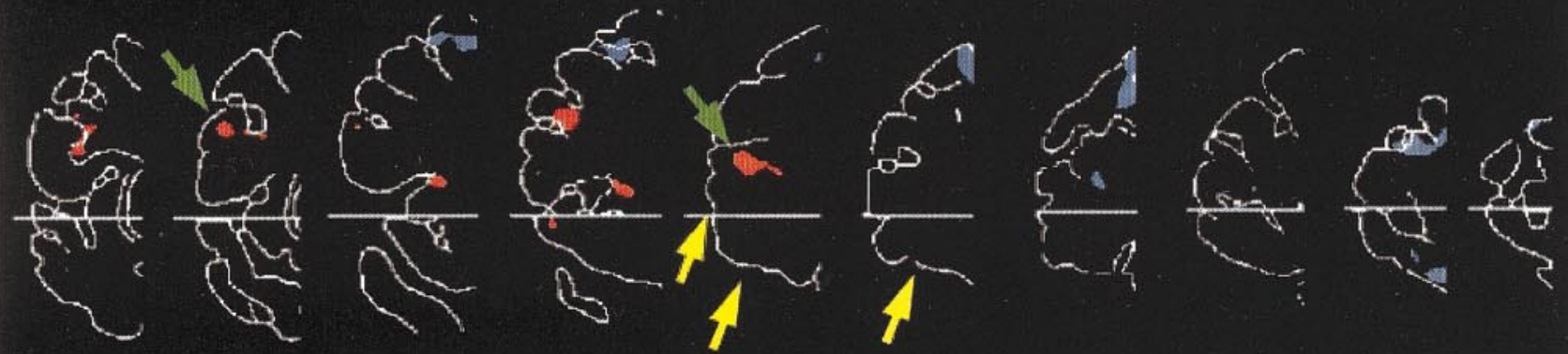

\section{Semantic vs. Phonological Judgment}
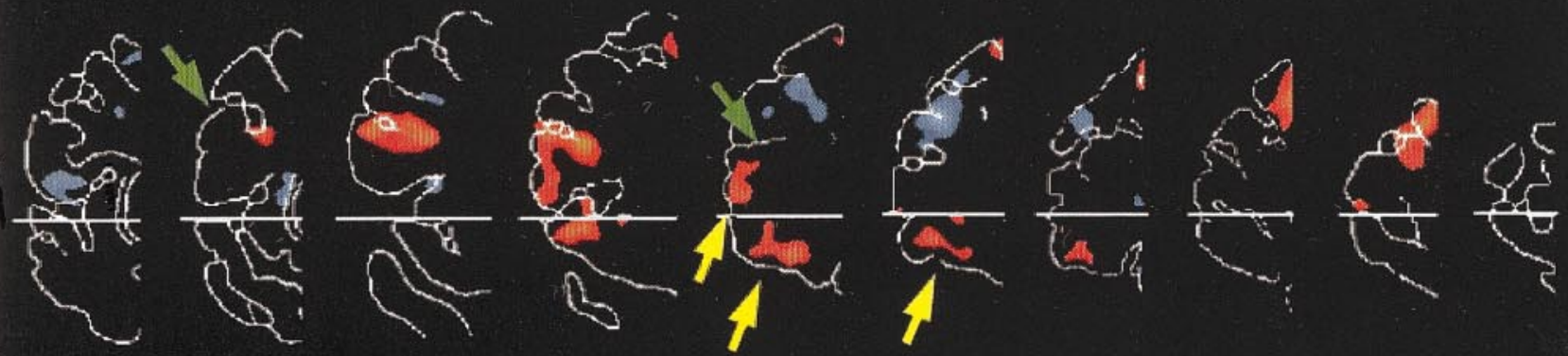

\section{Pseudoword Phonological vs. Case Judgment}
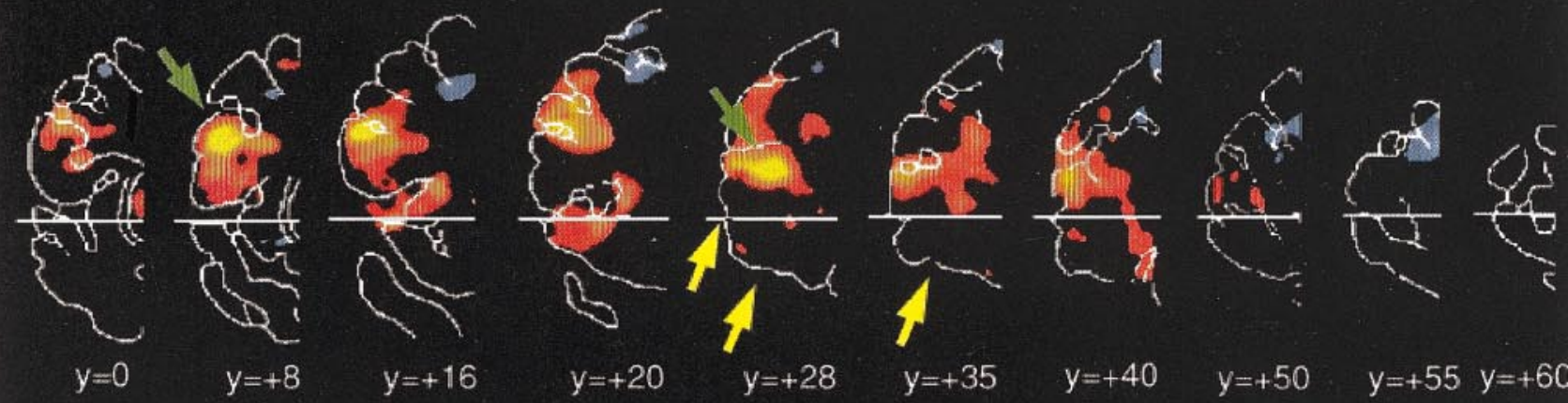

$$
p<10^{-8}
$$

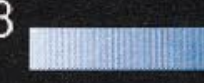

$$
\mathrm{p}<.05
$$

FIG. 2. Regions of significant activation in the left prefrontal cortex for each scan, averaged across subjects. Regions displayed

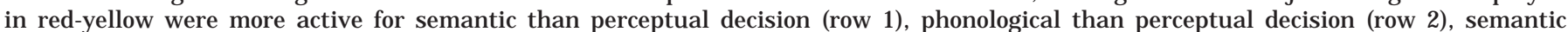

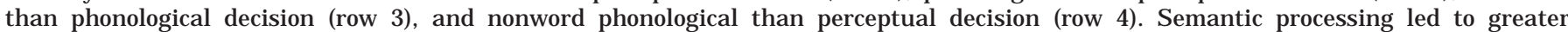


Semantic > Case

\section{Syllable > Case}

\section{Semantic > Syllable}

\section{Nonword Syllable > Case}
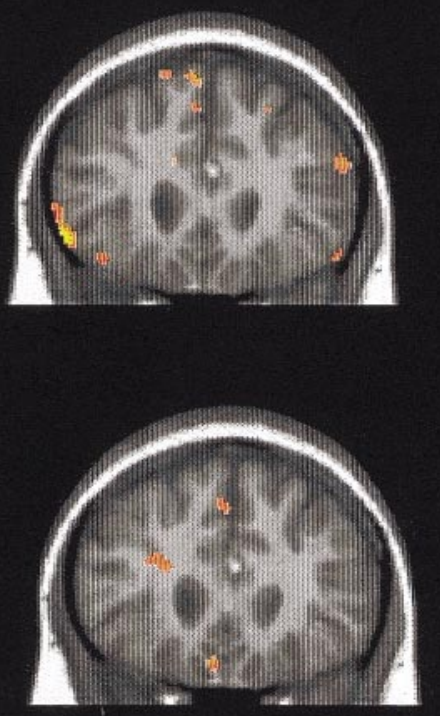

.0005

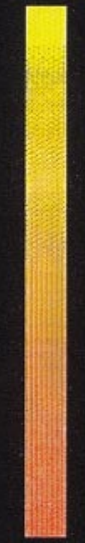

.025

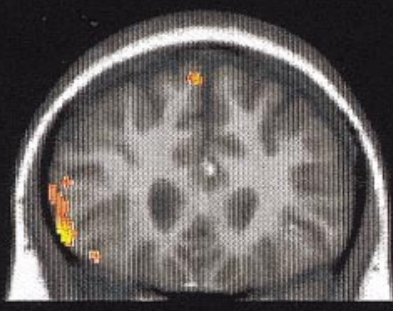

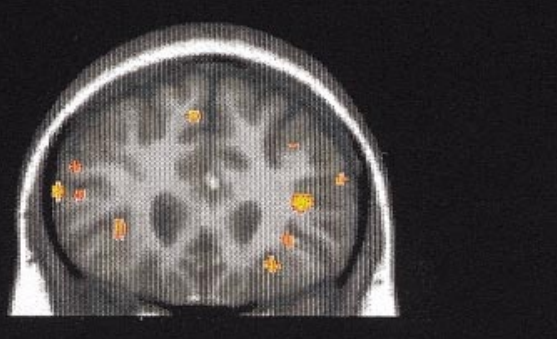

$\mathrm{R}$

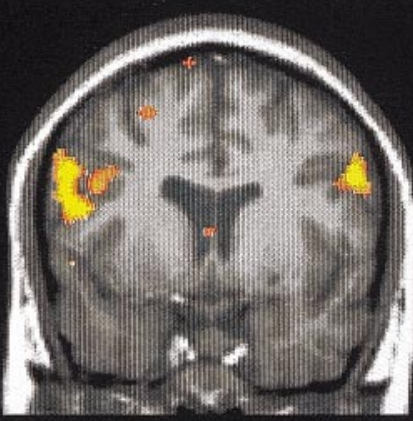

L

FIG. 3. Regions of significant activation in two selected slices for one individual subject in each scan. I mages are presented in neurol ogical convention (left side of image represents left hemisphere).

activity in ventral regions of the left inferior frontal gyus (BA 45/47, yellow arrows, slices 5 and 6), whereas both semantic and phonological processing engaged a dorsal region of the inferior frontal gyrus near the inferior frontal sulcus (BA 44/45, green arrows, slices 2 and 5). 
A report by Roskies et al. (1996) confirms the results of the present study. During PET scanning, four tasks were administered: easy and difficult semantic decision tasks, a synonym judgment task, and a rhyme judgment task. The LIPC was active during both the semantic decision and synonym tasks, and two regions in the LIPC were modulated by semantic task difficulty. Activation in the anterior/ventral region of LIPC (BA 47) was significant for the synonym task compared to fixation but not for the rhyme task compared to fixation, confirming the present results and previous findings by Shaywitz et al. (1995). Another study (Price et al., 1997) that compared phonological processing (syllable counting) and semantic processing (living-nonliving decision) found greater activation in BA 47 for semantic processing and greater activation in BA 44 for phonological processing when a lenient threshold was used.

\section{Process Specificity in Frontal Cortex: A Review}

In order to determine whether the observed difference in LIPC activation between semantic and phonological processing was evident across previous studies, we conducted a literature search in an attempt to find all brain imaging studies employing task comparisons designed to isolate semantic, phonological, or lexical processing. We characterized each task comparison in terms of several different categories: semantic decision (e.g., living-nonliving decision), semantic production (e.g., verb generation), lexical retrieval (i.e., word/ nonword decision, word-stem completion), phonological processing (e.g., phoneme monitoring or nonword processing), overt speech (e.g., word repetition or naming), and silent viewing of words. Activations were identified that fell roughly in the left frontal cortex (Talairach coordinates $\mathrm{X}<-15, \mathrm{Y}>0$, all $\mathrm{Z}$ ), and these activations plotted in saggital projection on a standard brain are presented in Fig. 4; a complete list of the studies included in this figure is provided in Appendix B.

This review demonstrates a great deal of overlap between the posterior regions active during semantic, phonological, and lexical processing (denoted by red circle in Fig. 4). However, a ventral and anterior region of the inferior frontal cortex (denoted by green circle in Fig. 4) was preferentially active during the performance of tasks requiring overt semantic processing. This region corresponds approximately to Brodmann's area $47 / 45$ and is located in the ventral extent of the inferior frontal gyrus, in the region where our study found activation for semantic relative to phonological processing. Semantic decision and generation tasks both resulted in activation of this region across studies, whereas there was little activity in this region during the performance of phonological and lexical tasks. There was, however, a significant amount of overlap in more posterior sections of the frontal cortex for semantic processing with those areas active for phonological and lexical processing, suggesting that semantic processing automatically engages those processes as well. Conversely, some activation on lexical and phonological tasks may reflect automatic semantic processing engaged during performance of those tasks, although this does not seem to be a common finding.

\section{The LIPC in Semantic Processing}

Given the current evidence that the LIPC is directly involved in semantic processing, it is important to ask what specific role it might play in this processing. Neuropsychological data demonstrate that patients with lesions to the LIPC, while being impaired on some tests of semantic processing (Swick and Knight, 1996), do not exhibit severe disturbances of semantic knowledge such as those seen following temporal lobe lesions. This suggests that the LIPC likely does not subserve the primary storage of semantic knowledge representations; rather, these representations are likely supported by temporal cortex (Damasio et al ., 1996; Price et al., 1997). The LIPC may serve instead as a semantic working memory system or semantic executive system (e.g., Gabrieli et al., 1996; Kapur et al., 1994b; Wagner et al., 1997a). The role of such a system would be to access, maintain, and manipulate semantic representations which are represented elsewhere in the cortex. This function is a semantic analogue to the spatial and object working memory functions that have been suggested for the prefrontal cortex on the basis of neurophysiology (Goldman-Rakic, 1987) and neuroimaging (Smith and J onides, 1997).

The semantic executive system may be engaged by three related forms of processing: retrieval, selection, and evaluation. Retrieval involves the arrangement of search cues and the querying of semantic storage for representations matching those cues. Selection involves the resolution of competition between retrieved representations and selection of the task-relevant attributes of these representations. Evaluation involves the synthesis of the information chosen through the retrieval and sel ection processes and use of this information to determine the proper response. Semantic tasks requiring a greater amount of semantic information require a greater amount of retrieval, whereas semantic tasks with many equally dominant competing responses, or those tasks involving decisions based upon specific attributes of the stimulus, require a greater amount of selection. The difficulty of evaluation processes should vary both with the amount of retrieved information and with the difficulty of the task (which may be related to selection).

It may be difficult to differentiate these processes, because increased retrieval necessarily results in increased selection and may also increase the load on the evaluation process. However, an fMRI study by Thompson-Schill et al. (1997) has suggested that activation of the LIPC is related to selection processes, specifically 
those processes related to the selection of task-relevant stimulus attributes. This study examined performance on semantic decision tasks in which certain features were selected and others had to be ignored (the HighSelection condition) and compared this to tasks in which all of the semantic features of the stimulus were relevant to task performance (the Low-Selection condition).

Comparison of these tasks demonstrated a region of the LIPC that was specifically related to selection demands when the difficulty of the high-selection and low-selection tasks (in terms of response time) was equated. This study is noteworthy in its attempt to further specify the processes that result in LIPC activation. However, the region found to be related to selection in the study by Thompson-Schill et al. (1997) fell predominantly in the posterior and dorsal portion of the inferior frontal gyrus (BA 44/45), which the review above suggested may be related to phonological or lexical processing. In one comparison there was a selection-related activation nearer to the anterior/ ventral inferior frontal region; this finding suggests that the selection hypothesis remains viable as an explanation of anterior/ventral LIPC activation, and further work must be done to ascertain whether the functional characteristics of this frontal region are consistent with this hypothesis. However, it is unclear whether tasks that require increased selection would also require increased semantic retrieval and/or evaluation processes. In addition, Vandenberghe et al. (1996) found activation of the LIPC in a task comparison that varied semantic retrieval demands but kept selection demands constant, suggesting that activation of this region may be directly related to retrieval rather than selection.

\section{Right Hemi sphere Activations}

Although our study focused on the particular role of the left inferior prefrontal cortex in semantic and phonological processing, consistent activation of the right inferior prefrontal region was also observed for both semantic and phonological processing compared to case judgments. A majority of participants exhibited bilateral activation for the semantic task compared to case judgment. Previous studies have found bilateral frontal activation for both semantic (e.g., Wagner \& al., 1998) and phonological (e.g., Pugh \& al., 1996) processing.

The right and left hemispheres may play different roles in the processing of phonological information. A study by Pugh et al. (1997) examined the relationship between lateralization of phonological processing using $\mathrm{fMRI}$ and regularity effects on lexical decision in the same subjects. Regularity effects refer to greater difficulty on a lexical decision task for irregular words, which do not follow orthographic-to-phonologic conversion rules (e.g. pint), compared to regular words, which follow these rules (e.g., lint). These effects are thought to reflect the operation of phonological recoding, in that the results of orthographic-to-phonologic conversion rules and the results of direct lexical access are in conflict for irregular items, resulting in extended response times. Pugh et al . (1997) found that the amount of right hemisphere activation during phonological processing was related to the size of regularity effects on a lexical decision task performed independently outside the scanner: Significant regularity effects were only found in subjects who exhibited bilateral inferior frontal activation. Effects of word length, which are also thought to reflect the operation of (serial) conversion rules, were also greater in subjects with greater right hemisphere activation.

These data suggest that the two hemispheres may process information differently during reading. Pugh et al. (1997) suggest that the two hemispheres may differ in the "grain size" of their processing, with the right hemisphere processing relatively small phonological units (such as individual phonemes) and the left hemisphere processing relatively large units (such as syllable onsets and rimes). The results of the present study suggest that the grain size of phonological processing in the right hemisphere may belarger than a single phoneme, since significant right hemisphere activation was found during performance of a task that required attention to larger phonological features. However, further experiments that directly manipulate critical word features (such as word length and regularity) are necessary to fully address this question.

\section{Frontal Regions and Phonological Processing}

The present findings extend previous results which had suggested a specific role for LIPC in phonological processing (e.g., Demonet et al., 1992; Zatorre et al., 1992) by suggesting that separate areas in the LIPC may befunctionally specialized for semantic and phonological processing (cf. Fiez, 1997). The posterior and dorsal region of the left IFG, corresponding to BA 44/45, may be specialized for phonological processing whereas the anterior region of the IFG (corresponding to BA 47/45) may be specialized for semantic processing. The present results also suggest that the syllable-counting task engages regions of the left frontal cortex that are roughly similar to those engaged by other phonological tasks, with greater activation during processing of pseudowords than real words.

It is unclear why the region of LIPC activation was so restricted during syllable counting with real words when compared to case judgments in the present study; much less activation was seen for this task comparison than for the comparison of semantic and case judgments. Response times for the phonological task did not differ from the semantic decision task, suggesting that the differences in activation did not arise from differences in gross task difficulty. It is likely that posterior regions outside the current scanning range were active during syllable counting with real words (Price et al., 

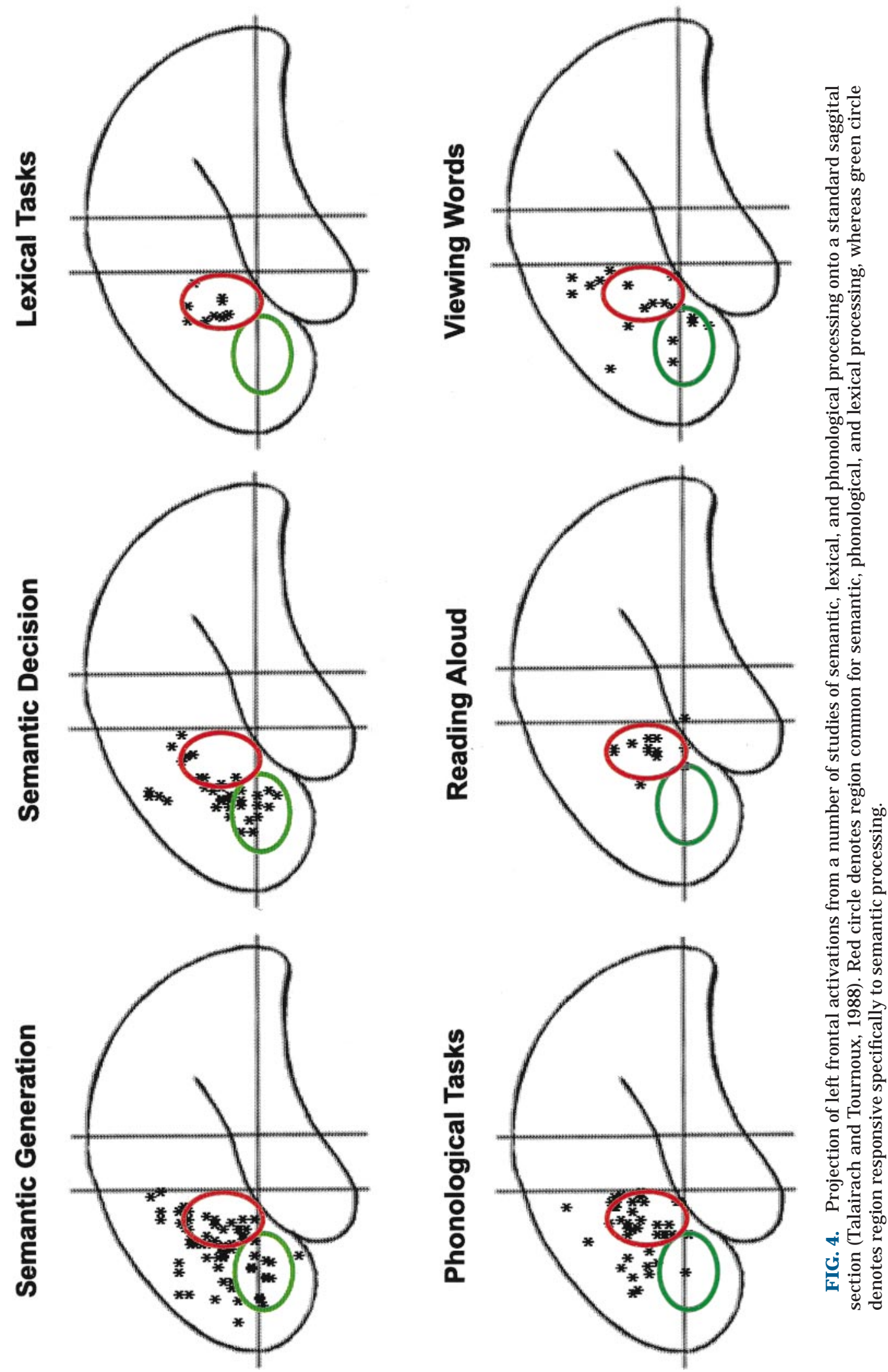
1997), and these regions may have primarily subserved task performance, with the frontal cortex playing a lesser role. The syllable-counting task using pseudowords also resulted in much greater frontal activation than the same task with real words. Syllable counting with real words may not have strongly engaged phonological recoding processes, which are necessary for the processing of pseudowords but not for real words. Syllable-counting judgments on real words may have instead been based upon orthographic knowledge; however, this is difficult to confirm on the basis of the current data.

Differences in activation were also observed between the syllable-counting tasks using words and pseudowords when each was separately compared to semantic processing using double subtraction. The largest difference between semantic and real-word syllable counting tasks was in the LIPC, whereas the strongest difference between semantic and pseudoword syllable-counting tasks was in the left superior frontal gyrus, with a weaker difference in the LIPC. It is unlikely that this difference in activations reflects qualitatively different underlying neural networks engaged in performance for real words and pseudowords during syllable counting. Rather, it is likely that the pseudoword phonological task engaged phonological processes more strongly than the real-word task. Because these phonological processes were also engaged by the semantic task, this attenuated differences in the LIPC when compared to the semantic task. The greater difference in the superior frontal cortex for the pseudoword task than for the real-word task occurred due to deactivation of the superior frontal region during pseudoword processing compared to case judgments, which may have been related to the attentional demands of the task. This suggests that common frontal regions were engaged during phonological processing on words and pseudowords, with greater engagement during the pseudoword task. Additional examination of the differences between word and pseudoword processing should shed further light upon the functional anatomy of phonological processing.

APPENDIX A: Stimulus Lists

\begin{tabular}{|c|c|c|c|}
\hline \multicolumn{4}{|c|}{ List 1} \\
\hline Abstract-2 Syllable & Abstract-N ot 2 Syllable & Concrete-2 Syllable & Concrete-Not 2 Syllable \\
\hline access & interim & apple & ACROBAT \\
\hline advice & INTERVAL & ARMY & ARM \\
\hline amour & intimate & BALLOON & BAR \\
\hline BURDEN & IRONY & bandit & CAR \\
\hline CHAOS & joy & BARLEY & cheek \\
\hline CONCEPT & LAW & baron & claw \\
\hline CRISIS & legacy & BUCKET & COAST \\
\hline DEMAND & LENIENCY & cabin & DROP \\
\hline DEMISE & LIBERTY & circle & emperor \\
\hline HEAVEN & LIFE & coffee & flood \\
\hline honor & love & collar & gallery \\
\hline IDEAL & LOYALTY & DIAMOND & GEESE \\
\hline issue & MASTERY & finger & GIRL \\
\hline LOGIC & melody & footwear & J AIL \\
\hline MADNESS & MEMORY & garment & knife \\
\hline MERCY & mind & glacier & ladybug \\
\hline METHOD & miracle & GOBLET & lake \\
\hline mischief & misery & GODDESS & LIBRARY \\
\hline MOVEMENT & MISTRIAL & lemur & lip \\
\hline namesake & MONTH & leopard & LUMP \\
\hline PHANTOM & mood & market & MONK \\
\hline REGRET & OBSTACLE & MONKEY & MUSICIAN \\
\hline remorse & occasion & MOTEL & nursery \\
\hline repose & opinion & NECTAR & opium \\
\hline REQUEST & origin & nephew & PLATE \\
\hline resolve & PAIN & noodle & rake \\
\hline RESPITE & PAST & oyster & scar \\
\hline RETURN & pep & pencil & SOIL \\
\hline safety & perjury & PORTAL & SPATULA \\
\hline snorkle & phobia & portrait & spoon \\
\hline sorrow & PHONETICS & sandals & STREET \\
\hline STANDARD & pledge & sergeant & TANK \\
\hline SUBSTANCE & poetry & SHOTGUN & TEA \\
\hline syntax & POLICY & SPIDER & thorn \\
\hline torment & position & steamer & TOMB \\
\hline VISION & POVERTY & trolley & TRACT \\
\hline
\end{tabular}


APPENDIX A-Continued

List 2

\begin{tabular}{|c|c|c|c|}
\hline Abstract-2 Syllable & Abstract-Not 2 Syllable & Concrete-2 Syllable & Concrete-Not 2 Syllable \\
\hline action & direction & BLIZZARD & admiral \\
\hline amount & disaster & bottle & AVENUE \\
\hline array & DISCRETION & BOULDER & banana \\
\hline belief & DIVISION & COLLEGE & boy \\
\hline BOREDOM & dream & CORNER & braid \\
\hline censure & DRUGGERY & DEVIL & brick \\
\hline CLIMAX & elegance & EXAM & cash \\
\hline conquest & embargo & FABRIC & CHILD \\
\hline CONTEXT & emotion & faucet & clock \\
\hline debate & END & flower & DISH \\
\hline deceit & EPISODE & fowl & drums \\
\hline DIVORCE & equation & gazelle & FLASK \\
\hline EFFORT & equity & HARDWOOD & foam \\
\hline FOLLY & EXERTION & hotel & FORM \\
\hline FREEDOM & FALLACY & infant & frog \\
\hline FULLNESS & FANTASY & kidney & GRASS \\
\hline harness & fate & LINDEN & ground \\
\hline kindness & fear & LION & HOSPITAL \\
\hline LIMIT & FRAUD & liver & KNIGHT \\
\hline menace & fright & lobster & KOALA \\
\hline MINUTE & fun & MEDAL & lawn \\
\hline MOMENT & gist & monarch & MAGAZINE \\
\hline OUTCOME & GORE & MONEY & meat \\
\hline percept & grade & mother & NAIL \\
\hline pleasure & gravity & mushroom & PLANT \\
\hline practice & GREED & NOVEL & pool \\
\hline PRESSURE & GRIEF & NUTMEG & РОТАТО \\
\hline PRESTIGE & health & PALACE & SLUSH \\
\hline prospect & heroism & PASTA & SNAKE \\
\hline RESULT & HISTORY & pepper & squash \\
\hline SCIENCE & holiness & poet & stick \\
\hline SILENCE & hope & poster & stone \\
\hline support & ILLUSION & RHINO & TEST \\
\hline trouble & INCIDENT & SKILLET & TOMATO \\
\hline VIGOR & INFERENCE & teacher & TREE \\
\hline welfare & INTELLECT & $\begin{array}{l}\text { TICKET } \\
3\end{array}$ & work \\
\hline Abstract-2 Syllable & Abstract-Not 2 Syllable & Concrete-2 Syllable & Concrete-Not 2 Syllable \\
\hline BEAUTY & abasement & BAGPIPE & ABDOMEN \\
\hline blessing & ADVANTAGE & BARREL & APPLIANCE \\
\hline cleanness & AFFECTION & baseline & BARNACLE \\
\hline CONFLICT & AFTERLIFE & bullet & BOARD \\
\hline COURAGE & age & camel & BOLT \\
\hline custom & AGONY & clothing & brain \\
\hline defeat & AMBITION & CRADLE & CAMP \\
\hline defense & AMNESIA & DECADE & cell \\
\hline DISEASE & ANARCHY & demon & $\mathrm{CHIN}$ \\
\hline DUTY & APTITUDE & dragon & COIN \\
\hline ESSENCE & AROUSAL & earring & cow \\
\hline ETHICS & attention & event & CROWN \\
\hline EXPENSE & attitude & FIORD & cucumber \\
\hline extent & betrayal & FOIBLE & face \\
\hline FEELING & BLAME & garden & fish \\
\hline figment & blasphemy & gibbon & FLAMINGO \\
\hline GAIETY & BRAVERY & grammar & FLEA \\
\hline gender & brevity & insect & FORK \\
\hline HATRED & CASUALTY & journal & GEM \\
\hline MARRIAGE & CENTURY & KETTLE & ghost \\
\hline meaning & chance & Iemon & head \\
\hline merit & choice & MAMMAL & HORSE \\
\hline MORAL & CLARITY & meadow & HOUSE \\
\hline
\end{tabular}


APPENDIX A-Continued

List 3

\begin{tabular}{|c|c|c|c|}
\hline Abstract-2 Syllable & Abstract-N ot 2 Syllable & Concrete-2 Syllable & Concrete-Not 2 Syllable \\
\hline OUTCRY & clemency & PAPER & MASK \\
\hline present & comedy & PICTURE & MILK \\
\hline rating & CONFIDENCE & PLAZA & morgue \\
\hline response & CREATION & prison & MOSS \\
\hline retreat & cruelty & pupil & MULE \\
\hline sadness & day & refuge & OATS \\
\hline session & death & reptile & peach \\
\hline STRUGGLE & DEDUCTION & sandwich & pole \\
\hline theory & DEITY & STUDENT & SAUCE \\
\hline UPKEEP & denial & TABLE & SCREEN \\
\hline valence & density & TIGER & skull \\
\hline VIRTUE & destiny & tower & steak \\
\hline worry & DIFFÚSION & tractor & steam \\
\hline \multicolumn{4}{|c|}{ Pseudowords } \\
\hline 2 Syllable & & Not 2 Syllable & \\
\hline accets & MERFER & abalyst & LABOFER \\
\hline ALARV & MIBOR & ALVOHOL & LAUTH \\
\hline ANCZOR & midut & AREWA & marifa \\
\hline ballov & mirgor & ARPERY & milsion \\
\hline baxten & motibe & barvier & NUPLEUS \\
\hline boptle & OWBER & bexefit & PHOPE \\
\hline CAGIN & panace & blabe & pigch \\
\hline CAGTLE & parase & branf & PODCH \\
\hline canver & PEPPEM & brunh & POEMRY \\
\hline canyor & PILKET & CALIGER & pounf \\
\hline censut & PLOTO & CHEWK & poyse \\
\hline CHAVEL & REHTAL & chorp & PRESIUM \\
\hline CHAVM & renime & CLITHE & quent \\
\hline CIRPLE & RULIRG & CLORE & REGIVAL \\
\hline coogie & SAREW & coaging & ROUNG \\
\hline corfee & SARING & creat & saviot \\
\hline CUSTOR & SERMOT & CRENT & SCHAP \\
\hline DEVIK & shuad & crogs & SHERF \\
\hline deway & sinnel & darce & SHILE \\
\hline ENFINE & sinxer & dengity & SHRITE \\
\hline FABOR & sixpy & DREPS & SMOLE \\
\hline facen & suine & edigion & SNOVE \\
\hline fanric & SUMSIT & episone & SPART \\
\hline figer & TACKIC & ESPEROR & speam \\
\hline FORELT & tepple & fastasy & speev \\
\hline giaft & TICKEP & FILHT & stilk \\
\hline heaben & TONTUE & finayce & streal \\
\hline HOWOR & TREAPY & frane & STROTE \\
\hline HUMOY & troply & galtery & TRAILEP \\
\hline HUPTER & truca & GRAIB & twiss \\
\hline imlact & tupnel & higoway & vession \\
\hline LAYTAN & VECSOR & IMPORA & VETESAN \\
\hline leston & VIRTIM & inquivy & wasce \\
\hline LORBY & virtin & insigat & WHEEG \\
\hline MASTEP & VONER & irogy & WHOKE \\
\hline mealow & voyame & juive & YOUSH \\
\hline
\end{tabular}


Buckner et al., 1995b

Buckner et al., 1995b

Buckner et al., 1995b

Buckner et al., 1995b

Buckner et al., 1995b

Buckner et al., 1995b

Buckner et al., 1995b

Buckner et al., 1995b

Buckner et al., 1995b

Klein et al., 1995

Klein et al., 1995

Klein et al., 1995

Klein et al., 1995

Klein et al., 1995

Klein et al., 1995

Klein et al., 1995

Klein et al., 1995

Klein et al., 1995

Klein et al., 1995

Klein et al., 1995

Klein et al., 1995

Klein et al., 1995

Klein et al., 1995

Martin et al., 1995

Martin et al., 1995

Martin et al., 1995

Martin et al., 1995

Martin et al., 1995

Martin et al., 1995

Martin et al., 1995

Martin et al., 1995

Petersen et al., 1989

Petersen et al., 1989

Petersen et al., 1989

Petersen et al., 1989

Raichle et al., 1994

Shaywitz et al., 1995

Shaywitz et al., 1995

Thompson-Schill et al., 1997

Warburton et al., 1996

Warburton et al., 1996

Warburton et al., 1996

Warburton et al., 1996

Warburton et al., 1996

Warburton et al., 1996

Warburton et al., 1996

Warburton et al., 1996

Warburton et al., 1996

Warburton et al., 1996

Warburton et al., 1996

Warburton et al., 1996

Warburton et al., 1996

Warburton et al., 1996

Warburton et al., 1996

Warburton et al., 1996

Warburton et al., 1996

Warburton et al., 1996

Warburton et al., 1996

Warburton et al., 1996

Warburton et al., 1996

Warburton et al., 1996

Warburton et al., 1996

Warburton et al., 1996

Warburton et al., 1996
Semantic Generation

Verb generation $>$ reading (females)

Verb generation $>$ reading (females)

Verb generation $>$ reading (males)

Verb generation $>$ reading (males)

Verb generation $>$ reading (females)

Verb generation $>$ reading (males)

Verb generation $>$ reading (females)

Verb generation $>$ reading (males)

Verb generation $>$ reading (males)

Synonym generation $>$ word repetition (L 1 )

Translation $>$ word repetition ( $L 1$ )

Synonym generation $>$ word repetition (L2)

Synonym generation $>$ word repetition (L 1)

Synonym generation $>$ word repetition (L2)

Translation $>$ word repetition (L 1)

Translation $>$ word repetition (L2)

Synonym generation $>$ word repetition (L1)

Translation $>$ word repetition (L 1)

Translation $>$ word repetition (L2)

Synonym generation $>$ word repetition (L2)

Synonym generation $>$ word repetition (L 2)

Translation $>$ word repetition (L 2)

Translation $>$ word repetition (L 1 )

Action word generation $>$ object naming

Color word generation $>$ object naming

Action word generation $>$ object naming

Color word generation $>$ object naming

Action word generation $>$ object naming

Action word generation $>$ object naming

Action word generation $>$ object naming

Color word generation $>$ object naming

Verb generation $>$ repeat word, visual word presentation

Verb generation $>$ repeat word, visual word presentation

Verb generation $>$ repeat word, auditory word presentation

Verb generation $>$ repeat word, visual word presentation

Verb generation $>$ repeat noun

Generate category exemplar > generate rhyme (silent)

Generate category exemplar > generate rhyme (silent)

Verb generation, high vs low selection

Verb generation $>$ noun generation

Verb generation $>$ rest (expt 3)

Verb generation $>$ rest

Verb generation $>$ rest (expt 2)

Verb generation $>$ listening

Verb generation $>$ rest (expt 3)

Verb generation $>$ silently repeat pseudoword

Verb generation $>$ rest (expt 3)

Verb generation $>$ rest

Verb generation $>$ rest

Noun generation $>$ rest

Verb generation $>$ rest

Verb generation $>$ verb/noun comparison

Verb generation $>$ rest

Verb generation $>$ listening

Verb generation $>$ silently repeat pseudoword

Noun generation $>$ rest

Verb generation $>$ rest

Verb generation $>$ rest (expt 2)

Verb generation $>$ verb/noun comparison

Verb generation $>$ rest (expt 2)

Verb generation $>$ silently repeat pseudoword

Verb generation $>$ listening

Verb generation $>$ verb/noun comparison

Verb generation $>$ rest (expt 2) $\begin{array}{lll}-49 & 29 & -2\end{array}$

$-43 \quad 21$

$-43 \quad 23$

$-43 \quad 35$

$-39 \quad 25$

$-39 \quad 43$

$-33 \quad 49$

$-31 \quad 23$

$-23 \quad 47$

$-52 \quad 24$

$-48 \quad 17$

$-48 \quad 22$

$-46 \quad 27$

$-44$

$-43$

$-42$

$-42$

$-42$

$-34$

$-32$

$-29$

$-28$

$-21$

$-43$

$-42$

$-42$

$-38$

$-36$

$-34$

$-32$

$-24$

$-42$

$-38$

$-33$

$-28$

$-43$

$-35$

$-22$

$-49$

$-52$

$-52$

$-48$

$-46$

$-46$

$-44$

$-44$

$-44$

$-42$

$-42$

$-42$

$-40$

$-40$

$-40$

$-38$

$-38$

$-38$

$-36$

$-36$

$-36$

$-34$

$-34$

$-32$

$-32$

$-30$
20

16

0

12

8

6
-2

$-2$

$-4$

27

29

26

12

15

12

22

$-6$

$-8$

31

6

$-3$

$-5$

$-21$

6

28

20

20

44

16

0

$-8$

20

8

$-6$

$-6$

13

8

8

30

16

12

16

24

24

28

5

4

14

4

24

28

4

2

32

32
-2

4

40

32

12

8

12 
APPENDIX B-Continued

\begin{tabular}{l}
\hline \\
\hline Warburton et al., 1996 \\
Warburton et al., 1996 \\
Wise et al., 1991 \\
Wise et al., 1991 \\
\\
Buckner et al., 1995b \\
Buckner et al., 1995b \\
Buckner et al., 1995a \\
Price et al., 1994 \\
Price et al., 1994 \\
Price et al., 1994 \\
Price et al., 1994 \\
Price et al., 1994 \\
Price et al., 1994 \\
Rumsey et al., 1997b \\
Rumsey et al., $1997 a$
\end{tabular}

Awh et al., 1996

Braver et al., 1997

Braver et al., 1997

Braver et al., 1997

Braver et al., 1997

Braver et al., 1997

Cohen et al., 1994

Cohen et al., 1994

Demonet et al., 1992

Demonet et al., 1994

Fiez et al., 1995

Fiez et al., 1995

Frith et al., 1995

Herbster et al., 1997

Herbster et al., 1997

J onides et al., 1997

J onides et al., 1997

J onides et al., 1997

Klein et al., 1995

Klein et al., 1995

Klein et al., 1995

Paulesu et al., 1993

Price et al., 1996b

Rumsey et al., 1997b

Rumsey et al., 1997a

Rumsey et al., 1997a

Rumsey et al., 1997a

Rumsey et al., 1997a

Sergent et al., 1992

Sergent et al., 1992

Sergent et al., 1992

Sergent et al., 1992

Sergent et al., 1992

Sergent et al., 1992

Sergent et al., 1992

Shaywitz et al., 1995

Warburton et al., 1996

Warburton et al., 1996

Warburton et al., 1996

Zatorre et al., 1992

Zatorre et al., 1992

Zatorre et al., 1996

Zatorre et al., 1996

Zatorre et al., 1996

Zatorre et al., 1996

Zatorre et al., 1996
Noun generation $>$ rest

Verb generation $>$ listening

Verb generation $>$ rest

Verb generation $>$ rest

Task comparison

$X$

$-28$

$-26$

$-40$

$-36$

Lexical Tasks

Stem completion $>$ fixation (females)

Stem completion > fixation (males)

Stem completion $>$ fixation

Lexical decision $>$ reading aloud

Lexical decision $>$ false font feature detection

Lexical decision $>$ reading aloud

Lexical decision $>$ false font feature detection

Lexical decision $>$ false font feature detection

Lexical decision $>$ reading aloud

Orthographic lexical decision $>$ fixation

Orthographic lexical decision $>$ fixation

$\begin{array}{lrl}-37 & 19 & 10 \\ -37 & 21 & 12 \\ -37 & 20 & 11 \\ -52 & 20 & 16 \\ -50 & 22 & 20 \\ -36 & 12 & 12 \\ -34 & 14 & 12 \\ -32 & 16 & 28 \\ -30 & 22 & 28 \\ -44 & 6 & 24 \\ -44 & 6 & 24\end{array}$

Phonological Tasks

2-back $>$ control

Monotonic increase with n-back load

Monotonic increase with n-back load

Monotonic increase with n-back load

Monotonic increase with n-back load

Monotonic increase with n-back load

1-back $>$ letter detection

1-back > letter detection

Phoneme monitor $>$ pitch monitor

Sequential ambig. phoneme match $>$ tone detection

Target detection $>$ fixation

Temporally changing $>$ temporally stable

Color monitoring, novel $>$ same pseudoword

Speak psueodword $>$ speak hiya repeatedly

Speak psueodword $>$ speak regular word

3-back > control

3-back $>$ control

3-back > control

Rhyme gen $>$ word repetition (L 1)

Rhyme gen $>$ word repetition (L 1)

Rhyme gen $>$ word repetition (L 1)

(Rhyme + consonant STM) > shape judgment

Pseudowords $>$ words, silent viewing

Phonological Idt $>$ fixation

Phonological LDT > fixation

Phonological LDT $>$ fixation

Phon. LDT > orthographic

Phon. LDT > orthographic

Letter-sound $>$ object processing

Letter-sound $>$ spatial processing

Letter-sound $>$ spatial processing

Letter-sound $>$ object processing

Letter-sound $>$ spatial processing

Letter-sound $>$ object processing

Letter-sound $>$ object processing

rhyme vs case

Silently repeat pseudoword $>$ rest

Silently repeat pseudoword $>$ rest

Silently repeat pseudoword $>$ rest

Phonetic discrimination $>$ passive speech listenening

Phonetic discrimination $>$ passive speech listening

Phonetic discrimination $>$ pitch disc.

Phonetic discrimination (half words) > listening to noise

Phonetic discrimination (half words) $>$ passive word listening

Phonetic discrimination (half words) > listening to noise

Phonetic discrimination (half words) $>$ passive word listening
$-42$

$-47$

$-42$

$-40$

$-38$

$-32$

$-36$

$-29$

$-50$

$-40$

$-40$

$-37$

$-44$

$-48$

$-44$

$-57$

$-44$

$-39$

$-44$

$-44$

$-40$

$-46$

$-42$

$-42$

$-42$

$-40$

$-36$

$-32$

$-58$

$-54$

$-52$

$-48$

$-44$

$-36$

$-25$

$-50$

$-48$

$-42$

$-38$

$-48$

$-34$

$-56$

$-56$

$-44$

$-43$

$-35$
Z

32

32

16

40

0

12

11

20

12

12

28

28

24

22

15

39

26

22

8

13

20

20

28

8

8

28

0

16

25

27

18

30

12

$-3$

16

24

20

20

20

8

4

6

5

18

21

12

18

48

20

16

$-2$

2

24

20

29

$-5$

27

27

21 
Binder et al., 1996

Binder et al., 1996

Demb et al., 1995

Demonet et al., 1992

Demonet et al., 1992

Demonet et al., 1992

Demonet et al., 1992

Demonet et al., 1992

Desmond et al., 1995

Gabrieli et al., 1996

J ennings et al., 1997

J ennings et al., 1997

J ennings et al., 1997

Kapur et al., 1994b

Kapur et al., 1994b

Kapur et al., 1994b

Kapur et al., 1994b

Kapur et al., 1994b

Kapur et al., 1994b

Pugh et al., 1996

Thompson-Schill et al., 1997

Thompson-Schill et al., 1997

Vandenberghe et al., 1996

Vandenberghe et al., 1996

Vandenberghe et al., 1996

Wagner et al., 1997

Wagner et al., 1997

Wagner et al., 1997

Wagner et al., 1997

Wagner et al., 1997

Wagner et al., 1997

Wagner et al., 1998

Wagner et al., 1998

Wagner et al., 1998

Wagner et al., 1998

Wagner et al., 1998

Wagner et al., 1998

Wagner et al., 1998

Wagner et al., 1998

Warburton et al., 1996

Herbster et al., 1997

Herbster et al., 1997

Martin et al., 1996

Martin et al., 1996

Martin et al., 1996

Martin et al., 1996

Martin et al., 1996

Price et al., 1994

Price et al., 1996a

Price et al., 1996a

Price et al., 1996a

Price et al., 1996a

Rumsey et al., 1997a

Bookheimer et al., 1995

Bookheimer et al., 1995

Bookheimer et al., 1995

Bookheimer et al., 1995

Menard et al., 1996

Menard et al., 1996

\section{Semantic Decision}

Semantic decision $>$ pitch decision

Semantic decision $>$ pitch decision

Abstract/concrete decision > case judgment

Semantic decision > pseudoword phonological decision

Semantic decision $>$ pseudoword phonological decision

Semantic decision $>$ pseudoword phonological decision

Semantic decision $>$ tone judgment

Semantic decision $>$ tone judgment

Abstract/concrete decision > case, left-lateralized Wada patients

Abstract/concrete decision > case judgment

PLS analysis, loads on semantic processing variable

PLS analysis, loads on semantic processing variable

PLS analysis, loads on semantic processing variable

Living/nonliving $>$ letter detection

Living/nonliving $>$ letter detection

Living/nonliving $>$ letter detection

Living/nonliving $>$ letter detection

Living/nonliving $>$ letter detection

Living/nonliving $>$ letter detection

Category match $>$ line judgment

Word similarity, high vs low selection

Word similarity, high vs low selection

Word \& Picture semantic match $>$ size match

Word $>$ picture, semantic match

Word \& Picture semantic match $>$ size match

First $>$ repeated, word, living/nonliving task

First $>$ repeated, picture, living/nonliving task

First $>$ repeated, word, living/nonliving task

First $>$ repeated, picture, living/nonliving task

First $>$ repeated, word, living/nonliving task

First $>$ repeated, picture, living/nonliving task

Abstract/Concrete decision > Fixation, single trial

Abstract/Concrete decision $>$ Fixation, single trial

Abstract/Concrete decision > U ppercase/L owercase

Abstract/Concrete decision $>$ U ppercase/Lowercase

Abstract/Concrete decision > U ppercase/L owercase

Abstract/Concrete decision > U ppercase/L owercase

Abstract/Concrete decision $>$ Fixation, single trial

Abstract/Concrete decision > U ppercase/L owercase

Verb/noun comparison $>$ rest

$-46 \quad 15$

$-45$

$-48$

$-20$

$-20$

$-18$

$-16$

$-16$

$-45$

$-49$

$-34$

$-34$

$-24$

$-38$

$-38$

$-32$

$-30$

$-38$

$-28$

$-50$

$-45$

$-41$

$-42$

$-34$

$-16$

$-49$

$-49$

$-47$

$-47$

$-39$

$-39$

$-50$

$-50$

$-43$

$-43$

$-40$

$-40$

$-31$

$-28$

$-40$

15
32

32
35

30

30

32

28

30

35

35

28

40

28

22

26

34

30

28

34

35

4

30

22

26

30

45

45

39

39

32

32

9

25

9

13

22

31

22

22

12

\section{Reading Aloud}

Speak word $>$ speak hiya repeatedly

Speak irregular word $>$ speak hiya repeatedly

Tool naming $>$ animal naming

Tool naming $>$ view nonsense objects

Animal naming $>$ view nonsense objects

Object naming $>$ view nonsense objects

Animal naming $>$ tool naming

read aloud $>$ false font feature detection

Repeating $>$ listening to words

Repeating words > saying crime to reversed words

Repeating words $>$ saying crime to reversed words

Repeating words $>$ saying crime to reversed words word $>$ pseudoword, pronunciation

$-46$

$-40$

$-52$

$-30$

$-28$

$-28$

$-26$

$-32$

$-58$

$-48$

$-42$

$-40$

$-18$

0
12

12
10

10
8

14

16

28

14

8

14

12

12

20

Viewing Words

View words $>$ view nonsense objects

View words $>$ view nonsense objects

View words $>$ view nonsense objects

name words $>$ view nonsense objects

View words $>$ view X's

View words $>$ view X's

$-40$

$-36$

$-32$

$-32$

$-49$

$-43$

26
18
14
18
10
20

30

3

15

44

40

36

44

40

9

9

4

0

$-8$

20

12

4

$-4$

16

$-4$

$-8$

30

8

20

20

$-12$

$-2$

4

$-4$

8

12

9

34

12

34

28

21

12

6

6

24

$-4$

$-4$

20

8

8

8

16

28

12

12

12

28

$-4$ 
APPENDIX B-Continued

\begin{tabular}{|c|c|c|c|c|}
\hline & Task comparison & $x$ & $\mathrm{Y}$ & Z \\
\hline Menard et al., 1996 & View words > view X's & -43 & 7 & 0 \\
\hline Menard et al., 1996 & View words > view fixation & -41 & 7 & 44 \\
\hline Menard et al., 1996 & View pictures $>$ view fixation & -39 & 10 & 20 \\
\hline Menard et al., 1996 & View words > view fixation & -39 & 20 & -4 \\
\hline Menard et al., 1996 & View pictures > view X's & -34 & 34 & 0 \\
\hline Petersen et al., 1990 & Real words > pseudowords & -29 & 43 & 0 \\
\hline Price et al., 1994 & Word $>$ false font, silent viewing & -38 & 28 & -16 \\
\hline Price et al., 1996b & Word > false font, silent viewing & -48 & 8 & 32 \\
\hline Price et al., 1996b & Word $>$ letter string, silent viewing & -42 & 28 & 20 \\
\hline Price et al., 1996b & Word $>$ letter string, silent viewing & -40 & 4 & 28 \\
\hline Price et al., 1996b & Word $>$ false font, silent viewing & -38 & 20 & 12 \\
\hline Price et al., 1996b & Word $>$ pseudowords & -26 & 46 & $2 \varepsilon$ \\
\hline Price et al., 1996b & Word $>$ pseudowords & -22 & 24 & $-\varepsilon$ \\
\hline
\end{tabular}

\section{REFERENCES}

Abdullaev, Y. G., and Bechtereva, N. P. 1993. Neuronal correlate of the higher-order semantic code in human prefrontal cortex in language tasks. Int. J . Psychophysiol . 14(3):167-177.

Abdullaev, Y. G., and Posner, M. I. 1998. Event-related brain potential imaging of semantic encoding during processing single words. Neurol mage 7:1-13.

Awh, E., J onides, J., Smith, E. E., and Schumacher, E. 1996. Dissociation of storage and rehearsal in verbal working memory: Evidence from positron emission tomography. Psychol. Sci. 7:2531.

Bookheimer, S. Y., Zeffiro, T. A., Blaxton, T., Gaillard, W., and Theodore, W. 1995. Regional cerebral blood flow during object naming and word reading. Hum. Brain Map. 3:93-106.

Braver, T. S., Cohen, J . D., Nystrom, L. E., J onides, J ., Smith, E. E., and Noll, D. C. 1997. A parametric study of prefrontal cortex involvement in human working memory. Neurol mage 5(1):49-62.

Buckner, R. L., Petersen, S. E., Ojemann, J . G., Miezin, F. M., Squire, L. R., and Raichle, M. E. 1995a. Functional anatomical studies of explicit and implicit memory retrieval tasks. J . Neurosci. 15:12-29.

Buckner, R. L., Raichle, M. E., and Petersen, S. E. 1995b. Dissociation of human prefrontal cortical areas across different speech production tasks and gender groups. J . Neurophysiol. 74:2163-2173.

Buckner, R. L. 1996. Beyond hera: Contributions of specific prefrontal brain areas to long-term memory retrieval. Psychonom. Bull. Rev. 3:149-158.

Caplan, D. 1992. Language MIT Press, Cambridge, MA.

Cohen, J. D., Forman, S. D., Braver, T. S., Casey, B. J., ServanSchreiber, D., and Noll, D. C. 1994. Activation of the prefrontal cortex in a nonspatial working memory task with functional MRI. Hum. Brain Map. 1:293-304.

Coltheart, M. 1985. The cognitive neuropsychology of reading. In Attention and Performance XI (M. I. Posner \& O. S. M. Marin, Eds.), Hillsdale, NJ : Erlbaum.

Damasio, H., Grabowski, T. J ., Tranel, D., Hichwa, R. D., and Damasio, A. R. 1996. A neural basis for lexical retrieval. Nature 380:499-505.

Damasio, A. R. 1992. Aphasia. N. Engl. J . Med. 326:531-539.

Demb, J . B., Desmond, J . E., Wagner, A. D., Vaidya, C. J ., Glover, G. H., and Gabrieli, J. D. E. 1995. Semantic encoding and retrieval in the left inferior prefrontal cortex: A functional mri study of task difficulty and process specificity. J . Neurosci. 15:5870-5878.

Demonet, J .-F., Chollet, F., Ramsay, S., Cardebat, D., Nespoulous, J .-L., Wise, R., Rascol, A., and Frackowiak, R. 1992. Theanatomy of phonological and semantic processing in normal subjects. Brain 115:1753-1768.

Demonet, J . F., Price, C., Wise, R., and Frackowiak, R. S. 1994. A PET study of cognitive strategies in normal subjects during language tasks: Influence of phonetic ambiguity and sequence processing on phoneme monitoring. Brain 117(Pt 4):671-682.

Desmond, J . E., Sum, J . M., Wagner, A. D., Demb, J . B., Shear, P. K., Glover, G. H., Gabrieli, J . D. E., and Morrell, M. J . 1995. Functional MRI measurement of language lateralization in wada-tested patients. Brain 118:1411-1419.

Fiez, J . A., Raichle, M. E., Miezin, F. M., Petersen, S. E., Tallal, P., and Katz, W. F. 1995. PET studies of auditory and phonological processing: Effects of stimulus characteristics and task design. J . Cog. Neurosci. 7:357-375.

Fiez, J . A. 1997. Phonology, semantics, and the role of the left inferior prefrontal cortex. Hum. Brain Map. 5:79-83.

Fiez, J . A., and Petersen, S. E. 1998. Neuroimaging studies of word reading. Proc. Natl. Acad. Sci. USA 95(3):914-921.

Francis, W. H., and Kucera, H. 1982. Frequency Analysis of English Usage: Lexicon and Grammar. Boston: Houghton Mifflin.

Friston, K. J ., J ezzard, P., and Turner, R. 1994. Analysis of functional mri time-series. Hum. Brain Map. 1:153-171.

Frith, C. D., Kapur, N., Friston, K. J ., Liddle, P. F., and Frackowiak, R. S. J. 1995. Regional cerebral activity associated with the incidental processing of pseudo-words. Hum. Brain Map. 3:153160.

Gabrieli, J . D. E., Desmond, J . E., Demb, J . B., and Wagner, A. D. 1996. Functional magnetic resonance imaging of semantic memory processes in the frontal lobes. Psychol. Sci. 7(5):278-283.

Gabrieli, J . D. E., Poldrack, R. A., and Desmond, J . E. 1998. The role of left prefrontal cortex in language and memory. Proc. Natl. Acad. Sci. USA 95:906-913.

Glover, G. H., and Lai, S. 1998. Self-navigated spiral fMRI: Interleaved versus single-shot. Magn. Reson. Med. 39:361-368.

Goldman-Rakic, P. S. 1987. Circuitry of primate prefrontal cortex and regulation of behavior by representational memory. I $\mathrm{H}$ Handbook of Physiology, Section 1, TheNervous System, Vol. V, Higher functions of the Brain, Part 1 (F. Plum and V. Mountcastle, Eds.), pp. 373-417. Am. Physiol. Soc., Bethesda, MD.

Hanley, J. R., and McDonnell, V. 1997. Are reading and spelling phonological mediated? Evidence from a patient with a speech production impairment. Cog. Neuropsychol. 14:3-33.

Herbster, A. N., Mintun, M. A., Nebes, R. D., and Becker, J . T. 1997. Regional cerebral blood flow during word and nonword reading. Hum. Brain Map. 5:84-92. 
I rarrazabal, P., Meyer, C. H., Nishimura, D. G., and Macovski, A. 1996. Inhomogeneity correction using an estimated linear field map. Magn. Reson. Med. 35(2):278-282.

J ennings, J . M., Mcl ntosh, A. R., Kapur, S., Tulving, E., and Houle, S. 1997. Cognitive subtractions may not add up: The interaction between semantic processing and response mode. Neurolmage 5(3):229-239.

Kapur, S., Craik, F. I. M., Tulving, E., Wilson, A. A., Houle, S., and Brown, G. M. 1994a. Neuroanatomical correlates of encoding in episodic memory: Levels of processing effect. Proc. Natl. Acad. Sci. USA 91:2008-2011.

Kapur, S., Rose, R., Liddle, P. F., Zipursky, R. B., Brown, G. M., Stuss, D., Houle, S., and Tulving, E. 1994b. The role of the left prefrontal cortex in verbal processing: Semantic processing or willed action? Neuroreport 5:2193-2196.

Klein, D., Olivier, A., Milner, B., Zatorre, R. J ., J ohnsrude, I., Meyer, E., and Evans, A. C. 1997. Obligatory role of the LIFG in synonym generation: evidence from PET and cortical stimulation. Neuroreport 8(15):3275-3279.

Klein, D., Milner, B., Zatorre, R. J ., Meyer, E., and Evans, A. C. 1995. The neural substrates underlying word generation: A bilingual functional-imaging study. Proc. Natl. Acad. Sci. USA 92(7):28992903.

Levelt, J . M. 1993. Speaking: From Intention to Articulation. Cambridge, MA: MIT.

Martin, A., Wiggs, C. L., Ungerleider, L. G., and Haxby, J . V. 1996. Neural correlates of category-specific knowledge. Nature 379:649652.

Martin, A., Haxby, J . V., Lalonde, F. M., Wiggs, C. L., and Ungerleider, L. G. 1995. Discrete cortical regions associated with knowledge of color and knowledge of action. Science 270:102-105.

Menard, M. T., Kosslyn, S. M., Thompson, W. L., Alpert, N. M., and Rauch, S. L. 1996. Encoding words and pictures: A positron emission tomography study. Neuropsychologia 34(3):185- 194.

Neely, J. H. 1977. Semantic priming and retrieval from lexical memory: Roles of inhibitionless spreading activation and limitedcapacity attention. J. Exp. Psychol. Gen. 106(3):226-254.

Noll, D. C., Pauly, J. M., Meyer, C. H., Nishimura, D. G., and Macovski, A. 1992. Deblurring for non-2D Fourier transform magnetic resonance imaging. Magn. Reson. Med. 25(2):319-333.

Paulesu, E., Frith, C. D., and Frackowiak, R. S. 1993. The neural correlates of the verbal component of working memory. Nature 362(6418):342-345.

Petersen, S. E., Fox, P. T., Posner, M. I., Mintun, M., and Raichle, M. E. 1988. Positron emission tomographic studies of the cortical anatomy of single-word processing. Nature 331:585-589.

Petersen, S. E., Fox, P. T., Snyder, A. Z., and Raichle, M. E. 1990. Activation of extrastriate and frontal cortical areas by visual words and word-like stimuli. Science 249:1041-1044.

Poldrack, R. A., Desmond, J . E., Glover, G. H., and Gabrieli, J . D. E. 1998. The neural basis of visual skill learning: An fMRI study of mirror-reading. Cereb. Cortex 8:1-8.

Price, C. J ., Wise, R. J . S., Warburton, E. A., Moore, C. J ., Howard, D., Patterson, K., Frackowiak, R. S. J ., and Friston, K. J. 1996a. Hearing and saying: The functional neuro-anatomy of auditory word processing. Brain 119:919-931.

Price, C. J ., Wise, R. J ., and Frackowiak, R. S. 1996b. Demonstrating the implicit processing of visually presented words and pseudowords. Cereb. Cortex 6(1):62-70.

Price, C. J ., Moore, C. J ., Humphreys, G. W., and Wise, R. S. J . 1997. Segregating semantic from phonological processes during reading. J . Cog. Neurosci. 9:727-733.

Price, C. J ., Wise, R. J ., Watson, J . D., Patterson, K., Howard, D., and
Frackowiak, R. S. 1994. Brain activity during reading: The effects of exposure duration and task. Brain 117(Pt 6):1255-1269.

Pugh, K. R., Shaywitz, B. A., Constable, R. T., Shaywitz, S. E., Skudlarski, P., Fulbright, R. K., Bronen, R. A., Shankweiler, D. P., Katz, L., Fletcher, J . M., and Gore, J . C. 1996. Cerebral organization of component processes in reading. Brain 119:1221-1238.

Pugh, K. R., Shaywitz, B. A., Shaywitz, S. E., Shankweiler, D. P., Katz, L., Fletcher, J. M., Skudlarski, P., Fulbright, R. K., Constable, R. T., Bronen, R. A., Lacadie, C., and Gore, J. C. 1997. Predicting reading performance from neuroimaging profiles: The cerebral basis of phonol ogical effects in printed word recognition. J . Exp. Psych. Hum. Percept. Perform. 23:299-318.

Raichle, M. E., Fiez, J. A., Videen, T. O., Macleod, A. M. K., Pardo, J . V., Fox, P. T., and Petersen, S. E. 1994. Practice-related changes in human brain functional anatomy during nonmotor learning. Cereb. Cortex 4:8-26.

Roskies, A., Fiez, J . A., Balota, D. A., Ojemann, J . G., Raichle, M. E., and Petersen, S. E. 1996. PET studies of semantic analysis. Soc. Neurosci. Abstr. 22:1110.

Rumsey, J . M., Horwitz, B., Donohue, B. C., Nace, K., Maisog, J . M., and Andreason, P. 1997a. Phonological and orthographic components of word recognition: A PET-rCBF study. Brain 120:739-759.

Rumsey, J. M., Nace, K., Donohue, B., Wise, D., Maisog, J . M., and Andreason, P. 1997b. A positron emission tomographic study of impaired word recognition and phonological processing in dyslexic men. Arch. Neurol . 54(5):562-573.

Sergent, J., Ohta, S., and Macdonald, S. 1992. Functional neuroanatomy of face and object processing: A positron emission tomography study. Brain 115:15-36.

Shaywitz, B. A., Pugh, K. R., Constable, R. T., Shaywitz, Bronen, R. A., Fulbright, R. K., Shankweiler, D. P., Katz, L., Fletcher, J. M. S. E., Skudlarski, P., and Gore, J . C. 1995. Localization of semantic processing using functional magnetic resonance imaging. Hum. Brain Map. 2:149-158.

Shaywitz, B. A., Shaywitz, S. E., Pugh, K. R., Constable, R. T., Skudlarski, P., Fulbright, R. K., Bronen, R. A., Fletcher, J. M., Shankweiler, D. P., Katz, L., et al. 1995. Sex differences in the functional organization of the brain for language. Nature373(6515): 607-609.

Shelton, J. R., and Weinrich, M. 1997. Further evidence of a dissociation between output phonological and orthographic lexicons: A case study. Cog. Neuropsychol . 14:105-129.

Smith, E. E., and J onides, J . 1997. Working memory: A view from neuroimaging. Cog. Psychol. 33(1):5-42.

Snyder, A. Z., Abdullaev, Y. G., Posner, M. I., and Raichle, M. E. 1995. Scalp electrical potentials reflect regional cerebral blood flow responses during processing of written words. Proc. Natl. Acad. Sci. USA 92(5):1689-1693.

Swick, D., and Knight, R. T. 1996. Is prefrontal cortex involved in cued recall? A neuropsychol ogical test of PET findings. Neuropsychologia 34:1019-1028.

Talairach, J ., and Tournoux, P. 1988. A Co-Planar Stereotactic Atlas of theHuman Brain. Thieme, Stuttgart.

Thompson-Schill, S. L., D'Esposito, M., Aguirre, G. K., and Farah, M. J . 1997. Role of left inferior prefrontal cortex in retrieval of semantic knowledge: A reevaluation. Proc. Natl. Acad. Sci. USA 94(26):14792-14797.

Van Orden, G. C., J ohnston, J . C., and Hale, B. L. 1988. Word identification in reading proceeds from spelling to sound to meaning. J . Exp. Psychol. Learn. Mem. Cog. 14(3):371-386.

Vandenberghe, R., Price, C., Wise, R., J osephs, O., and Frackowiak, R. S. 1996. Functional anatomy of a common semantic system for words and pictures. Nature 383(6597):254-256.

Wagner, A. D., Schacter, D. L., Rotte, M., Koutstaal, W., Maril, A., 
Dale, A. M., Rosen, B. L., and Buckner, R. L. 1998. Building memories: Remembering and forgetting of verbal experiences as predicted by brain activity. Science 281:1188-1191.

Wagner, A. D., Desmond, J. E., Demb, J. B., Glover, G. H., and Gabrieli, J . D. E. 1997a. Semantic repetition priming for verbal and pictorial knowledge: A functional MRI study of left inferior prefrontal cortex. J . Cog. Neurosci. 9:714-726.

Wagner, A. D., Buckner, R. L., Koutstall, W., Schacter, D. L., Gabrieli, J . D. E., and Rosen, B. R. 1997b. An fMRI study of within- and across-task item repetition during semantic repetition. Cog. Neurosci. Soc. Proc. 35.

Warburton, E., Wise, R. J ., Price, C. J ., Weiller, C., Hadar, U., Ramsay, S., and Frackowiak, R. S. 1996. Noun and verb retrieval by normal subjects: Studies with PET. Brain 119(Pt 1):159-179.
Wise, R., Chollet, F., Hadar, U ., Friston, K., H offner, E., and Frackowiak, R. 1991. Distribution of cortical neural networks involved in word comprehension and word retrieval. Brain 114:1803-1818.

Woods, R. P., Cherry, S. R., and Mazziotta, J. C. 1992. Rapid automated algorithm for aligning and reslicing PET images. J . Comput. Assist. Tomogr. 16:620-633.

Zatorre, R. J ., Meyer, E., Gjedde, A., and Evans, A. C. 1996. PET studies of phonetic processing of speech: Review, replication, and reanalysis. Cereb. Cortex 6(1):21-30.

Zatorre, R. J ., Evans, A. C., Meyer, E., and Gjedde, A. 1992. Lateralization of phonetic and pitch discrimination in speech processing. Science 256(5058):846-849. 